\title{
A MULTIPLE-GATE RUNNER SYSTEM FOR GRAVITY CASTING
}

\author{
Fu-Yuan Hsu ${ }^{1}$, Mark R. Jolly ${ }^{2}$ and John Campbell ${ }^{2}$ \\ ${ }^{1}$ Department of Materials Science and Engineering, National United University, \\ No.1 Lein-Da, Kung-Ching Li, MiaoLi, 36003 Taiwan, R.O.C. \\ ${ }^{2}$ Engineering School, University of Birmingham, Edgbaston, Birmingham B15 2TT, UK
}

\begin{abstract}
The L-shaped geometries in running and gating systems used in aluminium gravity casting have been investigated and optimised. Five geometries of L-junctions have been developed from which can be assembled complex multiple-gated runner systems. The change of direction through a right angle can yield a high coefficient of discharge, without entrapping detrimental oxide film defects because of the smooth flow, minimising surface turbulence. Progressive filling along the L-shaped geometry has been achieved by the optimisation of inside and outside curvatures of the junction to reduce the volume of the "dead zone". For each gate the coefficient of discharge, Cd, was measured, and the loss coefficient $\mathrm{K}$ for individual components was estimated. Uniform distribution of flow through each gate into a mould cavity has been demonstrated. A computational model showing the sequential filling profile of liquid metal along a multiple-gate runner was confirmed by real-time X-ray video of an aluminium alloy sand casting.
\end{abstract}

Keywords: aluminium gravity casting, multiple gates, runner system, coefficient of discharge 


\section{Introduction}

The purpose of a runner system is to achieve a desired flow rate into specific locations of a casting cavity, smoothly and efficiently. In the case of multiple gates it is essential that the liquid metal flows through each gate without developing detrimental oxide films and entrapping air bubbles in liquid metal. Clearly, such a high performance relies on a precise runner design which can direct the flow without leaving empty spaces or gaps within the runner geometry during the casting process. A runner geometry which precisely follows the profile of liquid metal stream, is the key to the quiescent and efficient filling of the mould cavity.

The concept used throughout this study was centred on the complete filling of the running system channels; all the wall surfaces of the system are designed to be in complete contact with the liquid metal; no gaps were permitted to develop during filling. If the liquid metal detaches from the walls, creating a space, surface turbulence would occur, entraining oxides and bubbles into the stream (Campbell, 2004, and Divandari and Campbell, 1999).

There is an additional complication in the sense that although the steady state flow might satisfy these conditions, oxide films could be generated during the initial transient, the priming of the channels of the system. During this early phase the liquid metal may not fill sequentially along the runner geometry but produce a chaotic mix of air and metal during the period until the priming phase is over and the air is totally expelled. In contrast, what is desired is a 'one-pass' filling condition, in which the liquid metal pushes the air ahead in the system, as a piston in a cylinder, and so does not mix with the air (Campbell, 2004).

Therefore, the elements of a good runner geometry are (i) fills in one pass and (ii) follows accurately the profile of the liquid metal stream. The formation of internal turbulence and oxide films can therefore be avoided and a high quality casting can be achieved.

In many castings multiple-gates are required, distributing liquid metal uniformly through each gate into the mould cavity. Traditional approaches to this design problem have met with mixed success. Johnson and Baker (1948) directly observed the filling process of molten steel in the running system by removing the copes of moulds. Multiple gates, such as finger, pencil, and horn shaped gates, were investigated. Motion pictures showed that, for all designs of multiple gates, most of the molten metal entered the mould cavity through the gate farthest from the sprue. Similar results could also be found elsewhere such as Johnson et al (1950, 1953), Grube and Eastwood (1950) and Webster (1964). The uneven filling from these gates probably results from the runner with a constant cross-sectional area throughout its length.

Campbell $(1991,2004)$ stressed that the stepping of a runner in an effort to redistribute flow more evenly through a succession of gates was not recommended because the melt tended to jump at each step, creating surface turbulence. Tapering of the runner avoided this problem. However, in those 
cases where tapering of the runner had been overlooked in a multiple gate system (for example: a three-gate system), the momentum of the flowing liquid causes the furthest gate (gate 3) to receive more liquid metal. The rapid flow past the opening of gate 1 will create a reduced-pressure region drawing liquid out of the casting. The flow may be either in or out of gate 2 , but at such a reduced amount as to probably be negligible.

Srinivasan (1962), using water model investigated two designs of step runner similar to that of Grube and Eastwood (1950). His results using a step runner, despite many efforts to vary cross sectional areas of various parts of the system, were not successful in obtaining a uniform flow distribution. Thus proportioning of the areas by trial and error methods clearly involves much effort and poor chance of success.

The study of Jeancolas et al (1962) clarified the theoretical principles of the reduction in runner cross-sectional area to ensure uniform metal flow through multiple gates based on the head loss coefficient of each gate. However, the coefficient of head loss could only be acquired experimentally.

Although until now a multiple-gated system has had to rely on a trial and error design, it still has been widely used. Not only do these gates provide metal over a large area of casting, thus reducing fluidity limitations, but also reduce the possibility of local overheating of the mould and reduce transverse horizontal velocities inside the mould (Campbell 2004). For example, the Cosworth system for the ingating of cylinder heads used ten ingates, although the excellent distribution obtained owed much to the counter-gravity flow of the metal (Campbell 1991).

This research was inspired to avoid the trial and error approach, and focuses therefore on the development of quantified guidelines for the design of multiple-gate systems. Requirements for a good running system with multiple gates are

1. Distribute the liquid metal uniformly into the mould cavity.

2. Avoid the entrainment of oxide or air

3. Reduce gate velocities

4. Maximise total flow rate as far as possible.

\section{METHOD}

The approach consisted of five parts: three 'virtual' studies and two physical experiments. These were:

1. L shaped junctions in 2-dimensions. A computational model was studied of a sprue-runner junction turning a right angle, represented as an L-shaped wall. The physical meaning of the 2D model is that the wall friction in the third dimension is zero. A unidirectional velocity of inlet-flow through the small inlet-opening on top of the domain was assumed (Figure 1). The falling jet turned 
freely from the vertical to the horizontal direction at the sprue base (Figure 3). In this 2D condition, the profile of this free transformation flow could be characterised by four dimensions ( $I, O, R_{i}$, and $\mathrm{R}_{\mathrm{b}}$ in Figure 1). The value of this approach is that an exact profile of the L-junction could be reproduced for any similar 2-D conditions.

2. $L$ shaped junctions in 3-dimensions. Based on the guidelines developed in the L-junction in 2D, the 3D sprue-runner L-shape junction was investigated. In the "physical" casting experiment of 3-D L-shape junctions, the loss coefficient $\mathrm{K}_{\mathrm{L}}$ of the L-shape sprue-runner junction was estimated and the coefficient of discharge $\mathrm{Cd}$ of this single-gate system was also measured.

2. Multiple-gate design. According to the guidelines developed in the $\mathrm{L}$ shaped junctions in $2 \mathrm{D}$, the 3D multiple-gate casting with several L-shape junctions was simulated computationally. In the "physical" experiment, the coefficient of discharge $\mathrm{Cd}$ of this multiple-gate system was determined.

\section{Computational modelling}

A computational fluid dynamics (CFD) code, Flow-3D, has been used for these studies. Flow-3D is based on the finite-volume-method, which was originally developed as a special finite difference formulation. Since the flow phenomena in running systems were mainly considered here, one fluid (i.e. liquid metal) with sharp interface tracking of a VOF algorithm was employed. Because the sand mold was assumed to have a high permeability, the generation of back-pressure from air and/or gas in the cavity during filling was neglected. Empty cells within a domain were therefore present as voids at no pressure (since atmosphere pressure was present throughout the filling process).

Isothermal conditions were assumed since the change of viscosity of the liquid could be ignored as approximately only 1 per cent of heat loss was expected (c.f., Richins and Wetmore, 1952). Thus, the energy equations for calculating heat transfer and solidification were excluded, concentrating our attention on the early stages of mold filling.

The simulations were carried out on a Silicon Graphics Octane (R10000-IP30) machine, running a $175 \mathrm{MHz}$ CPU and $640 \mathrm{MB}$ memory. The operating system was IRIX version 6.5 (Silicon Graphics). The input parameters, which were selected for the modeling of liquid alloy Al-7Si- $0.4 \mathrm{Mg}$ in the options of Flow-3D, have been listed previously (Hsu 2003, Yang et al 1998, 2000).

The simulation domain was divided into a mesh size of less than $1 \mathrm{~mm}$ per cell. The maximum adjacent cell size ratio was controlled within 1.17.

\section{$\underline{\text { Video X-ray radiography study }}$}

The main role of the video X-ray radiography was to verify the results of computational modeling. The technique has been described previously (Yang et al 1998, 2000). Sand molds were used so as to 
be transparent to X-rays. Molten Al-7Si-0.4Mg alloy was poured into the pouring basin, where a graphite-stopper was placed at the entrance of sprue. The basin was filled completely, signaled by the flow of the liquid into the overflow sump. At $750 \pm 5^{\circ} \mathrm{C}$, indicated by the thermocouple in the pouring basin, the stopper was abruptly lifted clear from the sprue entrance, permitting the start of filling. Additional molten alloy was poured continuously into the basin to maintain a constant head height in the basin during the filling of the casting. The radiographic video images were recorded at the speed of 50 frames per second.

\section{Coefficient of discharge}

In this study, the quantification of L-shape junction and multiple gate runners was established by the measurement of coefficient of discharge $\mathrm{Cd}$. This is the dimensionless ratio of the actual flow rate divided by the theoretical flow rate. The Cd value is, of course, always less than one since there are always head losses, equivalent to frictional losses, in the running system.

The actual discharge flow rate was estimated by the trajectory method in which the velocity of the liquid metal emerging from a horizontal channel was determined from measurements of the parabolic trajectory of the stream of liquid that issued from the end of the channel. The trajectories of the three exit streams from the three gates were recorded against a grid background with a high-speed camera.

If the head loss of a specific component in a running system were determined, the loss coefficient $\mathrm{K}$ (Equation 3) and $\left(L_{E} / D\right)$ the dimensionless equivalent lengths (Equation 2) for this component can be calculated.

\section{$\underline{\text { Head losses }}$}

Total head loss, $\mathrm{h}_{l T}$, is regarded as the sum of major losses, $\mathrm{h}_{l}$, due to frictional effects in fully developed flow in constant-area tubes, and minor losses, $\mathrm{h}_{l m}$, due to entrance, fittings, area changes, and so on. Thus,

$$
\mathrm{h}_{l T},=\mathrm{h}_{l}+\mathrm{h}_{l m} \quad \text { Equation 1 }
$$

The major head loss can be expressed as the pressure loss for fully developed flow through a horizontal runner of constant area. In laminar flow, the pressure drop may be computed analytically; however, in turbulent flow, we must resort to experimental results and dimensional analysis to correlate the experimental data. Therefore, the major head loss is defined as

$$
\mathrm{h}_{l}=\mathrm{f} \frac{L}{D} \frac{V^{2}}{2 g}
$$

Equation 2

where, $\mathrm{f}$ is the friction factor, $\mathrm{L}$ is pipe length, $\mathrm{V}$ is mean velocity, $\mathrm{D}$ is pipe diameter and $\mathrm{g}$ is gravitational acceleration. The experimental results for the friction factor is published by Moody (1944). In laminar flow, the friction factor, $f_{\text {laminar }}=64 / \mathrm{Re}$, is a function of Reynolds number only 
and is independent of roughness. In turbulent flow, the friction factor is the function of both of Reynolds number, $\mathrm{Re}$, and relative roughness, e/D.

As the flow passes through a varieties of fittings, bends, or abrupt changes in area, additional head loss are obtained as a result from local regions of intensive bulk turbulence. Energy, eventually, is dissipated by violent mixing in the regions. The minor head loss may be expressed as

$$
\mathrm{h}_{l m}=\mathrm{K} \frac{V^{2}}{2 g}
$$

Equation 3

where $\mathrm{K}$ is the loss coefficient, $\mathrm{V}$ is mean velocity, and $\mathrm{g}$ is gravitational acceleration. The loss coefficient $\mathrm{K}$ must be determined experimentally for each situation.

\section{PROCEDURE}

\section{$\underline{\text { L shaped junctions in 2-dimensions }}$}

One advantage of using computational modelling is that 2-dimensional problems can be quickly and easily studied whereas, in reality, of course, the friction on the wall in the third direction effectively means that no pure 2-dimensional condition exists. Two dimension conditions are expected to become good approximations for slot-shaped channels.

Using this useful modeling advantage, a series of 2-dimensional geometries were constructed to simulate parallel runners. A one-directional flow with a uniform velocity impacting on the perpendicular wall is shown in Figure 3. The consequential geometry of flow in and out of the junction can, if unhindered, develop a natural profile characterised by four measurements, "inlet-dimension I", "outlet-dimension O", "inner-radius $\mathrm{R}_{\mathrm{i}}$ ”, and "base-radius $\mathrm{R}_{\mathrm{b}}$ " (Figure 1). These measurements define the natural profile that we wish to replicate in the design of an L-shaped bend in a running system.

The flow entering the system is called "inlet-flow". The wall adjacent and parallel to the direction of the inlet-flow is named the "inlet-wall". In the case of an L-junction, the wall with a surface perpendicular to the inlet-wall is called "outlet-wall", adjacent to the "outlet flow". The point where the two walls intersect is defined as "the base point B".

The "inlet-dimension I" defines the thickness of inlet-flow. Similarly, the "outlet-dimension O" is the thickness of the outlet flow. These flow regions are joined by the naturally-formed curve, called the "inner-radius $\mathrm{R}_{\mathrm{i}}$ ". This radius was determined to a close approximation by the "three-point method" in which three arbitrary points on the curve were selected; and using a compass, a circle linking these points could be drawn. The distance between B and the circle was called the "base-radius $\mathrm{R}_{\mathrm{b}}$ ". 
The three basic variables, "Inlet-opening $\mathrm{I}_{0}$ “, "inlet-velocity $\mathrm{V}_{i}$ ”, and "inlet-flow direction $\mathrm{D}_{i}$ ” were systematically studied in order to characterize their influence on the design of the L-junction.

In the 2-dimension case, the Inlet-opening $\mathrm{I}_{\mathrm{o}}$ can be characterised by a single length dimension. For instance, the length is the thickness of the exit of the sprue (as its width, of course, is assumed infinite).

A series of 2D models of L-junctions of different geometry were studied as follows:

1. Inlet-opening $\mathbf{I}_{\mathbf{o}}$ included $1,4,8,12,16,20,24,28$, and $32 \mathrm{~mm}$.

2. Inlet-velocity $\mathbf{V}_{\mathbf{i}}$ included $1,2,4$, and $8 \mathrm{~m} \cdot \mathrm{s}^{-1}$.

3. Direction of gravity was defined as the negative direction of the $\mathrm{z}$-axis (i.e., $-\mathrm{z}$ ). The direction of the inlet-flow $\mathbf{D}_{\mathbf{i}}$ can have four different combinations in the vertical plane, and one variety in the horizontal plane. The five situations, "L1", "L2", "L3", "L4", and "L5-junctions", from the inlet-flow to the outlet-flow are illustrated in Figure 2. These junctions can all exist in running system designs. In this study only L1 and L5 junctions have been selected for detailed consideration. They are described as follows.

- "L1-junction": the direction of the inlet-flow is the same as the gravity (-z) and the direction of the outlet-flow is either in the positive or negative direction of $\mathrm{x}$-axis in the $\mathrm{X}-\mathrm{z}$ coordinate; (e.g., $(-\mathrm{z}) \rightarrow(+\mathrm{x}$ or $-\mathrm{x})$.)

- "L5-junction": the flows are within the $x-y$ horizontal plane (e.g., $( \pm x) \leftrightarrow( \pm y)$.) meaning that gravity does not influence the flow in the system.

In summary, this approach constrains one side of the flow stream and measures the profile of the other free side in a 2-dimensional condition.

\section{$\underline{L}$ shaped junctions in 3-dimensions}

\section{L-shape in modelling}

The L1-junction represents the common sprue-runner junction in a gravity casting. To validate the 2-D design a 3-dimensional computational model (named "L-shape") was used, depicted in Figure 4. Using a velocity boundary condition with uniform one-direction flow from the top of the domain, the geometry of the tapered sprue was constructed according to conservation of mass. Therefore, the $260 \mathrm{~mm}$ high hyperbolic sprue, topped with a $40 \mathrm{~mm}$ deep basin, giving an entrance velocity into the sprue of $0.891 \mathrm{~m} \cdot \mathrm{s}^{-1}$ resulted in a total head height of $300 \mathrm{~mm}$.

\section{L-shape in real casting (single-gate system)}

A real casting of the "sprue-runner junction" (Figure 6) was also investigated. The dimensions also followed the guidelines found in modeling results for designing the L1-junction. The square sprue with $20 \%$ increase of the theoretical area of the top section was used (this is a 'safety measure' 
typical of sprue designs used in foundries to encourage the complete filling of the sprue by this modest increase in the sprue taper). A similar total head height of $300 \mathrm{~mm}$ was used. A video X-ray radiography study and measurement of the coefficient of discharge were carried out.

\section{Bend-shape in modelling}

A similar geometry, "Bend-shape" (Figure 5), with a reduced area "A", was modelled to compare with the former simple "L-shape" junction. An appropriate area reduction relies on a precise knowledge of the geometry of the main stream. However, the shape of the main stream could not be predicted unless a particular runner is first defined. Here, for convenience, an outer-radius, tangential to the inlet- and the outlet-walls, was constructed and the width of the channel in the middle of the bend was approximated by averaging both $\mathrm{I}$ (inlet-dimension) and $\mathrm{O}$ (outlet-dimension) of the L-shape.

\section{Multiple-gate design}

An application of the principle of the L-junction geometry was used in the design of a multiple gated system, as shown in Figure 7. Every bend in the geometry can be seen to be an L-junction. Therefore, from the sprue to the gates, there are four L-junctions, one L1-junction and three L5-junctions. The cross-sectional area of the horizontal runner was equal to the total cross-sectional area of the three identical gates. The total distance from the base of the sprue to the exit of each of the three gates was also made equal at $254 \mathrm{~mm}$ in order to provide the same head loss in the different passages.

Three different types of investigations were conducted using the same multiple-gate geometry. These were (i) computational modelling; (ii) real-time X-ray radiography, and (iii) calculation of the coefficient of discharge. The pouring basin with an over-flow sump and $20 \%$ increase of the theoretical top area of the sprue were included. For all the investigations, the total head height of 300 mm was used.

\section{RESULTS}

\section{$\underline{L}$ shaped junctions in 2-dimensions}

For $\mathrm{L} 1$ and $\mathrm{L} 5$ junctions, the result of three dimensions (i.e. $\mathrm{R}_{\mathrm{b}}, \mathrm{R}_{\mathrm{i}}$, and $\mathrm{O}$ ) normalized by dimension $\mathrm{I}$, as a function of the inlet-velocity $\mathrm{V}_{\mathrm{i}}$ is shown in Table 1 and Figure 8 and 9.

\section{$\underline{L}$ shaped junctions in 3-dimensions}

Three experiments for sprue-runner junction designs are investigated in this section. There were two 
models, L-shape (dimensions given in Figure 4) and Bend-shape (Figure 5), and one real casting (Figure 6).

\section{L-shape model}

The simulation results of the 3D L-shape in its centre plane are shown in Figure 10. By 0.13s, the liquid metal filled completely the hyperbolic-shaped square-sprue. Also, the flow front was seen to advance progressively, leaving only small, transient empty regions in its wake, but these were quickly filled. At $0.31 \mathrm{~s}$, the whole running system was completely filled and the average velocity of the flow at the exit of the horizontal runner was higher than $2.5 \mathrm{~m} / \mathrm{s}$, the highest velocity magnitude scale in red colour.

\section{L-shape casting (single-gate system)}

Figure 12 shows the experimental results of a series of frames taken by video X-ray radiography. At the time frame of $0.16 \mathrm{~s}$, the flow entered the L-shape junction. At $0.28 \mathrm{~s}$, the junction was completely filled.

To estimate the velocity at the end of the runner, the trajectory method (Figure 13) was adopted (air resistance to the trajectory was neglected). Figure 14 demonstrated the estimated velocity for the trajectory of the aluminium liquid, issued from the end of runner, against to time. (N.B. Time zero started as the flow first emerged from the runner, which is different from the start time of the X-ray radiography.) It showed the velocity of the flow was the highest, $2.23 \mathrm{~m} \cdot \mathrm{s}^{-1}$, at $0.08 \mathrm{~s}$. After this peak velocity, the flow quickly fell to a constant velocity, around $1.69 \mathrm{~m} \cdot \mathrm{s}^{-1}$, at $0.4 \mathrm{~s}$. At $3.16 \mathrm{~s}$, the velocity started to decline until the end of flow around 4.5s. Due to the scale and the spacing between graduations, the error of measurement could be up to $\pm 2.63 \mathrm{~mm}$ corresponding to a potential error in the velocity of $\pm 0.11 \mathrm{~m} \cdot \mathrm{s}^{-1}$.

Considering the flow rate exiting the runner, the coefficient of discharge of this system could be calculated from its total head height, $300 \mathrm{~mm}$, and actual velocity of the trajectory, $1.69 \pm 0.11 \mathrm{~m} \cdot \mathrm{s}^{-1}$. Making the assumption that the end of the runner is fully filled, and therefore the exit section of the stream is the section of the runner $\mathrm{A}$, the coefficient of discharge $\mathrm{Cd}$ is;

$$
\mathrm{Cd}=\frac{\text { Actual flow rate }}{\text { Theoretical flow rate }}=\frac{A \times V_{o}}{A \sqrt{2 g h}}=\frac{1.69}{\sqrt{2 \times 9.81 \times 0.300}} \approx 0.70 \pm 0.05
$$

To estimate the flow rate, the exiting flow was collected and weighed as $2.78 \pm 0.10 \mathrm{~kg}$. Taking the average velocity to be approximately $1.69 \mathrm{~m} \cdot \mathrm{s}^{-1}$, taken to apply for approximately $4.0 \mathrm{~s}$ (allowing for the short initial and final transients) gives therefore;

Actual flow rate $=\mathrm{Ag}_{\mathrm{g}} \cdot \mathrm{V}_{\mathrm{m}}=\frac{W}{\rho \times t}=\frac{2.78}{2430 \times 4.0}=2.86 \times 10^{-4} \mathrm{~m}^{3} \cdot \mathrm{s}^{-1}$ 
The cross-sectional area of the gate $\left(A_{g}\right)$ is $162 \mathrm{~mm}^{2}$ giving a mean velocity in the gate $V_{m}=1.77$ $\mathrm{m} \cdot \mathrm{s}^{-1}$ in fair agreement with the observed value of $1.69 \mathrm{~m} \cdot \mathrm{s}^{-1}$, and an estimated coefficient of discharge $\mathrm{Cd}=0.73$, which is close to 0.70 assessed by the trajectory method.

\section{Bend-shape model}

Figure 11 shows the results of the Bend-shape in the centre plane. Again, before $0.13 \mathrm{~s}$, the flow gradually filled the square-sprue down its hyperbolic shape. At 0.31 , the whole running system was filled without the creation of any empty regions at any time. The average velocity of the flow at the end of horizontal runner was less than $2.5 \mathrm{~m} / \mathrm{s}$ judging by the color in the velocity magnitude scale.

\section{Multiple-gate design}

Three results relating to the multiple-gate design were the simulation, the video $\mathrm{X}$-ray radiography study, and the coefficient of discharge.

\section{Multiple gate simulation}

Up to 0.10 s the liquid metal flowed progressively along the sprue, filling its cross section. At $0.10 \mathrm{~s}$, the flow entered the sprue-runner junction (the top of the runner). The results in an isotropic view (Figure 15) further reveal that at $0.12 \mathrm{~s}$ the flow impacted the base of the runner creating empty regions in the sprue. At $0.17 \mathrm{~s}$, the sprue was completely filled. At $0.25 \mathrm{~s}$, the flow in the first gate was completely filled. However, there was an empty region in the runner between the point $\mathrm{B}$ of the first L-junction and the side of inner-radius of the second L-junction; and the last two gates were still partially filled. In the next two time frames, $0.26 \mathrm{~s}$ and $0.27 \mathrm{~s}$, the last gate and the second gate were fully filled sequentially.

\section{Multiple gate casting}

Figure 17 shows the real-time $\mathrm{X}$ - radiography in the top view of the multiple gates. At $0.12 \mathrm{~s}$, the flow impacted the first L-junction, and it impacted on the second and third ones at 0.16s. Empty regions arrived and disappeared until 1.08s when flow streamed away from the multiple gates under the action of its inertial forces.

The trajectories of the three streams exiting the end of the three gates were recorded with a high speed camera, as shown in Figure 18. The dimensions of these trajectories were measured at each time frame, allowing the velocity versus time relation to be drawn (Figure 19). Here, it should be noted that the time of $0.04 \mathrm{~s}$ is equivalent to the time of $0.20 \mathrm{~s}$ of the video X-ray radiography for the top view of the multiple gates. The flow in the third gate exited first at this instant. This figure illustrates that the flows from the first and second gates came out later in that order. Therefore, 
initially, the velocity of the flow in the third gate is the highest while that in the second gate is the slowest. At $0.32 \mathrm{~s}$ (equivalent to $0.52 \mathrm{~s}$ in the radiography), the velocities of these three streams equalized and had a constant value of $1.64 \pm 0.09 \mathrm{~m} \cdot \mathrm{s}^{-1}$, lasting for $0.20 \mathrm{~s}$. At $0.52 \mathrm{~s}(0.72 \mathrm{~s}$ in the radiography), the velocities reduced, but remaining identical for all gates.

Considering the total head height of $300 \mathrm{~mm}$ in this multiple-gates system, the theoretical velocities of these three streams are equal to $2.43 \mathrm{~m} \cdot \mathrm{s}^{-1}$. Therefore, the coefficient of discharge $\mathrm{Cd}$ in this system is

$\mathrm{Cd}=\frac{\text { Actual flow rate }}{\text { Theoretical flow rate }}=\frac{\left(A_{1}+A_{2}+A_{3}\right) \times V_{o}}{\left(A_{1}+A_{2}+A_{3}\right) \sqrt{2 g h}}=\frac{1.64}{\sqrt{2 \times 9.81 \times 0.300}} \approx 0.68$

where the launch velocity $V_{o}$ in each gate is the same; and the individual cross-sectional areas, $A_{1}$, $A_{2}$, and $A_{3}$, apply to each numbered gate respectively.

\section{DISCUSSION}

\section{$\underline{\text { L shaped junctions in 2-dimensions }}$}

From the 2-D results, the five different geometries (Figure 2) are intended as design guidelines covering all types of L-shape junctions.

Without the influence of gravity in L5-junctions (i.e., x-y coordinates), the result of Table 1, for the $\mathrm{R}_{\mathrm{b}}, \mathrm{R}_{\mathrm{i}}$, and $\mathrm{O}$ against to $\mathrm{I}$, shows that these dimensions do not change with increasing inlet-velocity $\mathrm{V}_{\mathrm{i}}$. The ratio of the dimensions, which are the base-radius $\mathrm{R}_{\mathrm{b}}$, the inner-radius $\mathrm{R}_{\mathrm{i}}$, and the outlet-dimension $\mathrm{O}$, as a multiple of the inlet-dimension I remain fixed at 2.11, 1.42, and 0.99 respectively. Figure 9 the ratio of the outlet-dimension $\mathrm{O}$ over the inlet-dimension I being 0.99 , close to unity, implies that in the condition that gravity plays no role, the inlet and outlet dimensions and velocities remain the same.

In contrast the L1- junction is affected by gravity as it is clear in Figure 2. However, in Figure 9, it is also clear that the effect is not large, and effectively become negligible at velocities much above 4 $\mathrm{m} \cdot \mathrm{s}^{-1}$.

Based on the normalized ratios in the Table 1 , if one of the four dimensions, $I, O, R_{i}$, and $R_{b}$, is decided, the rest of these dimensions can be identified immediately from the ratios (Table 1). Assume that a tapered square section down-runner and square section runners are used. In practice, several procedures for re-generating L-junctions could be followed.

1. Find a suitable L-junction. Note the direction of inlet-flow relative to that of gravity, to select the appropriate system (from L1 to L5).

2. Determine the total head height of the whole running system. The total head height depends not 
only on the casting geometry, but also on the requirement of the flow rate into the mould cavity.

3. Apply an appropriate inlet-velocity $\mathrm{V}_{\mathrm{i}}$. If the total head height is decided, the inlet-velocity into a L-junction could be approximated by the height from the top to the point, where the flow enters the junction.

4. Decide the outlet-dimension O. According to the requirement of flow rate into cavity, the size of the outlet-dimension could be decided as it accompanies with the other two factors, the chosen velocity into the cavity and the width of the runner. In fact, the expected velocity could be simply estimated by the total height. The width of the runner would affect the size of the bottom of the tapered square sprue because the width of the runner is equal to one side of the bottom area of the sprue (c.f., Figure 6). A suitable size of the width there relies on appropriate choice of the sprue size.

5. Then, the rest of the dimensions of the L-junction could be determined based on Table 1 . Here, the scheme used is to reproduce the profile of the L-junction if the same conditions are met. By tailoring the exact shape of the junction, the runner walls would contain the flow completely. Even so, we need to note that in the exercise described in this work, only two walls (i.e., the inlet-wall and the outlet-wall) constrained the flow, whilst the inner side of the flow remained open to the free space of the runner. We are now applying these results to a real situation where the flow would be confined by walls on all sides.

This raises a series of questions: is the flow affected by the additional wall (i.e., the inner wall)? If yes, does it alter the shape of the L-junction? Naturally, this additional wall would increase the friction of the flow, reducing its velocity. However, it does not mean that the shape of flow stream would change. The majority of the flow would be concentrated in the centre of the runner while the velocity of the flow near the wall would be expected to be much slower. The additional, relatively small, influence of friction will assist the channel to remain fully filled by a slight overcompensation, conferring a reassuring factor of safety for the complete filling of the channel.

\section{$\underline{\text { L shaped junctions in 3-dimensions }}$}

The objective of this study is to verify the guideline developing previously by re-generating the exact geometry of L1-junction and fitting in the position of the sprue-runner junction in "real" and "virtual" experiments. Improving the L-junction geometry by reducing the area of "dead zone" in the corner of the junction, creating the bend-shaped junction, was also tested in computational modelling. Coefficient of discharge of this single-gate system was measured in order to determine the magnitude of the head losses of the L1-junction.

\section{L-shape and Bend-shape in modelling}

In the modelling of the L-shape of sprue-runner junction, the flow enters the geometry at $0.13 \mathrm{~s}$. At $0.24 \mathrm{~s}$, this geometry is completely filled. Thus, the duration of filling this geometry, the "clean-up" time, is $0.11 \mathrm{~s}$. It is far less time than that required in the sprue-runner junctions designed by Grube $e t$ 
al (1952), in which their optimum "clean-up" time is between 1 and 3 seconds for their sprue base designs of flat, enlargement, and well. Their designs were focused on increasing the volume in the impact area by providing a 'well'. For all of their designs the angle of sprue-runner junction is 90 degrees with a little fillet or without. It is important to note that in comparison with a 'well', the L-shape and bend-shape junctions gives almost zero opportunity for the entrapment of air into the running system.

The location of the reduction volume in the Bend-shape design is actually a part of the circulating flow, or so-called "dead-zone", within the L-shape. In Figure 10, the main stream flows toward the side of the inner-radius and there is a region of circulating flow in the corner between the inlet-wall and outlet-wall. Therefore, based on the dimension of L-junction design accompanied with the reduction region ( "dead-zone"), an ultimate bend shape could be produced (Figure 11).

\section{L-shape in a real casting}

In the results of the real casting of the L-shape, Figure 14 shows that during the initial transient flow, the velocity briefly touched the maximum value $2.23 \mathrm{~m} \cdot \mathrm{s}^{-1}$. This velocity approaches the theoretical velocity $2.43 \mathrm{~m} \cdot \mathrm{s}^{-1}$ for a free fall from the total head height of $300 \mathrm{~mm}$ as a result of the jet not totally contacting the surfaces of the walls of the running system in the early phase of the filling. This is confirmed in the real-time X-ray radiography (Figure 12) showing empty regions in the base of the junction. After impacting the base of the runner, the deflected shoots as a mainly free jet toward the exit of the runner. Thus its trajectory is largely free from frictional drag resulting in a jet with the velocity close to theoretical as observed.

From the beginning of entering the junction at $0.16 \mathrm{~s}$ to the fully filled condition at $0.28 \mathrm{~s}$ the "clear-up" time of the L-shape junction was $0.12 \mathrm{~s}$ At this time the velocity of the trajectory began to decline, as shown in Figure 14, reaching a steady state value of $1.69 \mathrm{~m} \cdot \mathrm{s}^{-1}$ at $0.40 \mathrm{~s}$ until approximately $3.0 \mathrm{~s}$.

Traditionally, the coefficient of discharge of the system and loss coefficient of the L-shape junction are introduced, in order to compare to those of other running systems. An exact coefficient relies on a correct measurement of actual flow velocity. In this study, the velocity estimated by the trajectory method is $1.69 \pm 0.11 \mathrm{~m} \cdot \mathrm{s}^{-1}$, and the estimated coefficient of discharge Cd is $0.70 \pm 0.05$.

Like the L-shape junction here, various single-gate systems, summarised by Ruddle (1956) and Srinivasan (1962), find Cd over 0.70, but with wide variations in the values of Cd (i.e., 0.55 0.75 and $0.54 \sim 0.76$ respectively). The value of $\mathrm{Cd}$ is highly sensitive to the geometry of the system, explaining the scatter in results. The low values of $\mathrm{Cd}$ often reflect the incomplete filling of the running system, which was largely not appreciated in these early studies. It is therefore more useful to understand the individual head losses of each of the components of the system if further calculation has to be made. 
The intention of this investigation was to determine the loss coefficient $\mathrm{K}$ of the L-shape junction. Yet the loss coefficient of other components, such as sprue entrance, sprue, and the horizontal runner, in this system were not determined, but derived from previous studies (Johson et al 1953, Richins and Wetmore 1952, Ruddle 1956 ). The detailed calculations of the loss coefficient of the L-shape junction was made elsewhere (Hsu 2003). For this running system, the estimation of the head losses and the loss coefficients of the individual components are summarized in Table 2.

In the system in this study, the energy head loss of the L-shape junction is approximately $0.016 \mathrm{~m}$ (or within $0.001 \sim 0.028 \mathrm{~m}$ ) while the minor loss coefficient $\mathrm{K}_{\mathrm{L}}$ of this junction is 0.110 (or within 0.007 0.192). Compared to results by previous authors, $\mathrm{K}_{\mathrm{L}}$ is surprisingly small even when the maximum value of 0.192 is assumed; for instance, Richins and Wetmore (1952) reported a loss coefficient of 0.4 for their optimized smooth radius bend.

In the application of hydraulic systems, losses for flow through valves and fittings also may often be expressed in terms of the equivalent length of straight pipe. Based on the major loss equation (i.e., $f$ $\frac{L_{E}}{D} \frac{\bar{V}^{2}}{2 g}$ ), the dimensionless equivalent lengths $\left(L_{E} / D\right)$ of the L-shape junction therefore is 2.75 (or in the range of $0.175 \sim 4.8$ ) as the friction factor $f$ of 0.04 is considered. This is very close to that of the ball valve (c.f. Fox and McDonald 1994).

\section{Multiple-gates design}

The objective of this study was to check the applicability of the guidelines in a real multiple-gate example using L1-junction for the sprue-runner junction and three L5-junctions for the direction changes on the horizontal surface. Coefficient of discharge of this system was measured in order to determine the magnitude of the head losses of this system.

Comparing the results of the computational simulation and the real-time X-ray radiography, generally, the modelling appeared to give identical profiles of the flow to the real casting at the various stages. However, the simulation lost some details of flow phenomena in particular situations.

1. First, the filling time in the modelling is always less than that in the real casting. The duration, between the flow, impacting on the base of the sprue, and the stream in the third gate coming out, is $0.12 \mathrm{~s}$ while that in the real-time $\mathrm{X}$-ray radiography appears $0.20 \mathrm{~s}$. This problem also was found in the benchmark test of Flow-3D modeling, as Barkhudarov and Hirt (1995) tried to use a value for the molecular viscosity five times larger than that of pure aluminium to prolong the filling time from the original predicted modelling time of $1.5 \mathrm{~s}$ to the experimental time of $2.2 \mathrm{~s}$. In this study, original molecular viscosity was employed, possibly explaining why the filling 
time in the modelling is less. Furthermore, the modelling conditions were assumed to be isothermal and one-fluid (i.e. no air). Without these influences the filling time in the modelling is less than that in real casting, since the solidification of flow and the back-pressure in cavity also play some roles in the increase of the filling time.

2. At the time frame of $0.20 \mathrm{~s}$ in the radiography (Figure 17) (which is equivalent to $0.22 \mathrm{~s}$ in the modelling, Figure 16), the outlet-flow in the second L5-junction breaks away from the surface of the outlet-wall and contacts the surface in the inner side of this junction. This is different from that in the model where the flow is always against to the surface of the outlet wall. This discrepancy is possibly due to the relatively coarse mesh used. The detail in the flow phenomena was sacrificed as appropriate rough meshes were used in order to reduce the computational time, already long at $\sim 48$ hours.

3. Third, in the modelling, the gap next to the side of the inner-radius in the second L5-junction was closed by the back flow at time frame of $0.26 \mathrm{~s}$, and after this time, there is no gap in the system. However, in the real-time X-ray radiography, the gap within the second junction is closed only for 0.20 s (i.e., within the period $0.52 \mathrm{~s} \sim 0.72 \mathrm{~s}$ in the radiography). For each of the streams coming from the each gate, the velocity estimated by the trajectory method is the same and is around $1.64 \mathrm{~m} \cdot \mathrm{s}^{-1}$. After the time frame of $0.72 \mathrm{~s}$, the gap began to increase. In fact, the pressure head in the pouring basin only maintains a constant of $300 \mathrm{~mm}$ until $0.72 \mathrm{~s}$. After this time, the head height fell as the pouring basin emptied at the end of the pour. In contrast to the experimental conditions, of course, the constant boundary condition can be applied throughout the computational model allowing no chance for a gap to form again once a steady state of filling was acheived.

As a result of the high pressure built up in the outlet-wall of the first L5-junction (Figure 16) the flow near the point B in the first L5-junction is separated from the surface of the inner side of the second L5-junction. An equivalent gap forms in the entrance of the second L5-junction.

To reduce the influence of the pressure built up in the outlet-wall of the first L5-juntion, the reduction area on the L-shape junction such as the Bend-shape in the previous section could be used here. Three ways for improvements of multiple gates runner are suggested in Figure 20. In Figure 20a the sharp cusps at the entrances to the separate channels would, of course, required to be radiussed. In Figure 20b if the form of the separated main stream (depicted in red colour) in the entrance of the second L5-junction could be precisely measured, the exact form of the junction could be provided in the tooling to prevent, the separation of the flow.

Finally, in figure 20c, the channels are separated. The flow is therefore distributed at a much earlier stage such at the exit of the sprue. The pressure between the inlet-wall and the outlet-wall within each L5-junction would not interfere with each other and would comply with the original condition 
of each of the separate L-shape junctions. Practically, it might be achieved by the assembling several single-gates (with equal lengths and numbers of L-junctions) into a multiple-gate system. Such designs of filling system are occasionally employed in which a number of separate sprues originate in the pouring basin, and supply metal at the same time by lifting several stoppers.

In many designs of multiple-gate system, such as the systems by Johnson and Baker (1948), Johnson et al (1950, 1953), Grube and Eastwood (1950) and Webster (1964), most of the liquid metal entered the mould cavity through the gate farthest from the sprue. The uneven filling into the mould cavity through the multiple gates often results in a danger of entrapment of air and oxides.

In this study, although the velocity in each gates came out differently in the early stage of filling (Figure 19) in the trajectory experiment, after the flow becomes steady the velocities of three streams from gates are equal. Even as the pressure head drops in the pouring basin, velocities of three streams slow at the same rate. The flow rate for each stream appears to remain the same despite the different lengths of each flow path, probably as a result of the much greater influence of the cross-sectional area of the channels being equal.

Similarly, an even flow rate from each gate can be achieved in a system with three consecutive L5-junctions assembled from one straight runner, such as a stepped (or better, tapered) runner in earlier works.

This explains why many authors (e.g., Srinivasan 1962, Grube and Eastwood 1950) suggest using the step runner, which is reducing the cross-sectional area along the runner, to improve the even flow rate into the cavity.

Furthermore, the coefficient of discharge $\mathrm{Cd}$ in this system is 0.68 . In comparison, a similar system by Srinivasan (1962) indicated a Cd of only 0.49 probably as a result of several incompletely filled regions observed in his multiple-gate system.

\section{CONCLUSIONS}

1. Guidelines for the designing of L-junctions are developed. Five different orientations of L-junctions can represent all directions of junctions in a 2-D system. These can be assembled in the design of runners and multiple-gate systems.

2. Progressive filling of the L-junction geometry can be improved by reducing the area of the "dead zone" by converting to Bend type junctions. Bends have higher friction and advantageously reduce the speed of flow.

3. In a multiple-gate system uniform distribution of flow rate through each gate into the mould cavity can be achieved by assembling various L-junctions with same number and same distance of the runner. 
4. Quantification of a running system is established by the measurement of coefficient of discharge $\mathrm{Cd}$. For the complete single-gate system with an L-shape sprue-runner junction the $\mathrm{Cd}$ is 0.70 . For the multiple-gate system the $\mathrm{Cd}$ is 0.68 . An overall frictional loss of 30 per cent may be generally applicable for all filling systems are remain fully filled.

5. For the individual sprue-runner junction (L-junction), the loss coefficient $\mathrm{K}_{\mathrm{L}}$ is 0.110 and the dimensionless equivalent length $\left(L_{E} / D\right)$ is 2.75 .

\section{ACKNOWLEDGEMENTS}

F-Y Hsu acknowledges the help of Jean-Christophe Gebelin, Nan-Woei Lai, H.S.H. Lo and Masood Turan, A. Caden and Jörg Pfeiffer, and the sponsorship of the Overseas Research Students Awards Scheme (ORS) of UK Universities.

\section{REFERENCES}

Barkhudarov M.R., Hirt C.W., 1995, Casting simulation: mold filling and solidification- benchmark calculations using Flow-3D®, Modeling of Casting, Welding and Advanced Solidification Processes VII, pp.935-946

Campbell J., 1991, Castings, Butterworth-Heinemann, pp. 42-43.

Campbell J., 2004, Castings Practice the 10 rules of castings, Elsevier Butterworth-Heinemann, pp.39-40; pp.44.

Divandari M., Campbell J., 1999, The Mechanism of Bubble Damage in Castings, 1st Int. Conference on Gating, Filling and Feeding of Aluminum Castings, AFS society, Oct. 11-13, 49-63. Flow-3D, Flow Science, http://www.flow3d.com

Fox R.W., McDonald A.T., 1994, Introduction to fluid mechanics, Fourth edition, John Wiley \& Sons, pp.341

Grube K., Eastwood L.W., 1950, A study of principles of gating, Trans. AFS, v.58, pp.76-107.

Hsu F.-Y., 2003, Further Development of Running System for Aluminium Castings, PhD thesis, The University of Birmingham, U.K.

Jeancolas M., Cohen de Lara G., Hanf H., 1962, Hydrodynamics study of horizontal gating systems, Trans. AFS, v.70

Johnson W.H., Baker W.O., 1948, Gating systems for metal castings, Trans. AFS, v.56, pp.389-397. Johnson W.H., Baker W.O., Pellini W.S., 1950, Principles of gating design: factors influencing molten steel flow from finger gating systems, Trans. AFS, v.58, pp.661-668.

Johnson W.H., Bishop H.F., Pellini W.S., 1953, Velocities and volume rates of metal flow in gating systems, Trans. AFS, v.61, pp.439-450

Johnson W.H., Bishop H.F., Pellini W.S., 1953, Velocities and volume rates of metal flow in gating systems, Trans. AFS, v.61, pp.439-450.

Moody L.F., 1944, Friction factors for pipe flow, Trans. ASME, 66,8, Nov., pp.671-684. 
Richins D.S., Wetmore W.O., 1952, Hydraulics applied to molten aluminum, Trans. ASME, July, pp.725-732.

Ruddle R.W., 1956, The running and gating of sand castings: a review of the literature, Institute of Metals, Monograph and Report Series No.19

Srinivasan M.N., 1962, Applied hydraulics to gating systems, Ph.D. thesis, The University of Birmingham, U.K.

Webster P.D., 1964, A study of the flow of metal in gating systems, The British Foundryman, v.57, Oct., pp.442-450.

Yang X, Jolly M.R., Campbell J., 2000,Minimizations of surface turbulence during filling using a vortex-flow runner, Aluminium Transactions, 2 (1), 67-80.

Yang X., Din T., Campbell J., 1998,Liquid metal flow in molds with off-set sprue, Int. J. Cast Metals Res., 11, 1-12. 


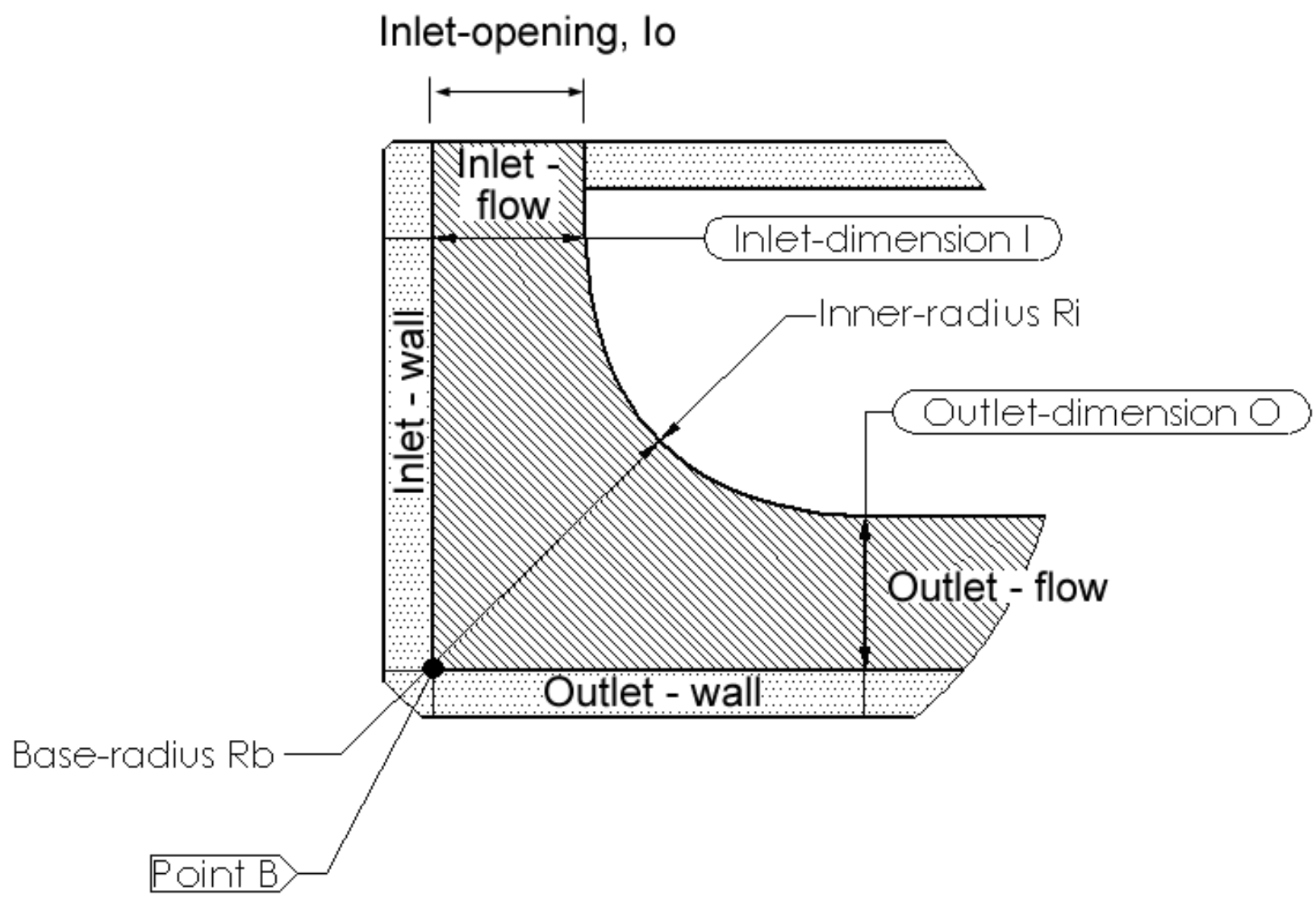

Figure 1 the profile of transition flow determined by the four dimensions (i.e., $I, O, R_{i}$, and $R_{b}$ ). 

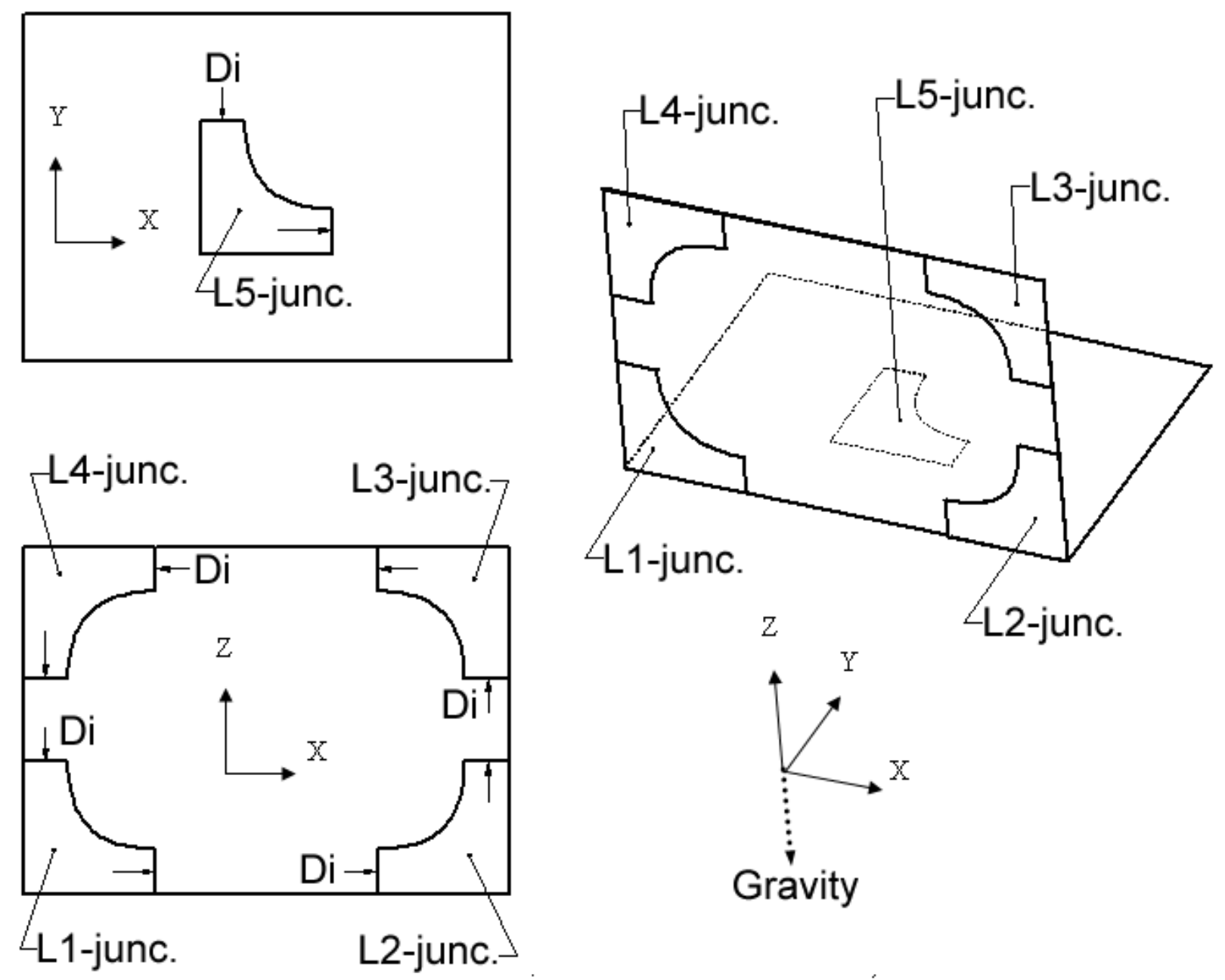

Figure 2 the schematics of five situations for the 2-dimensional L-junction as the direction of inlet-flow $\mathbf{D}_{\mathbf{i}}$, relatively to that of the gravity (i.e., the negative z-direction), is considered. Within a system of L-junction, two arrows indicate the inlet-flow and outlet-flow. 


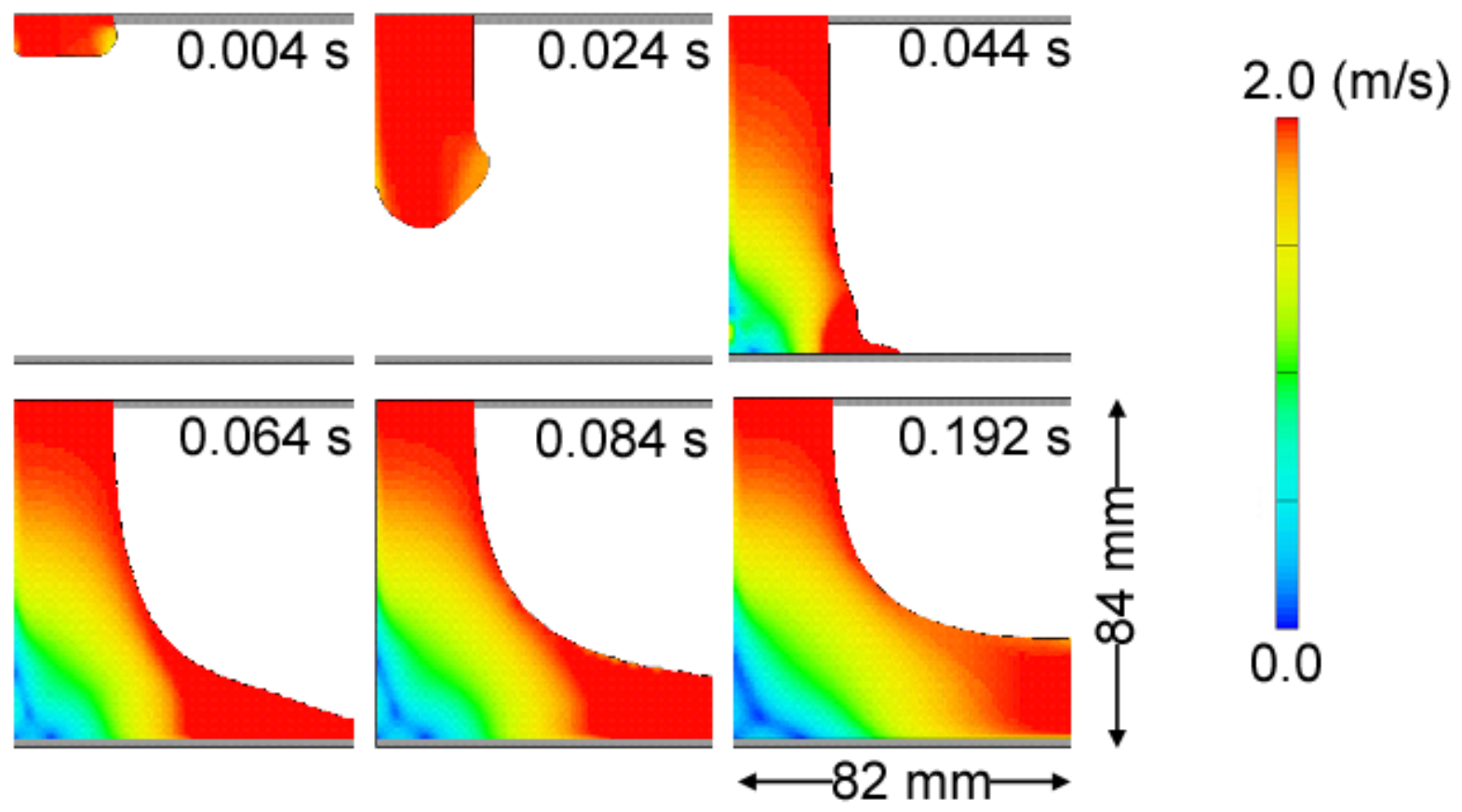

Figure 3. A series of frames for the 2D modelling result of the L5-juncton $V_{\mathbf{i}} 2 \mathbf{I}_{\mathbf{o}} \mathbf{2 4}$.

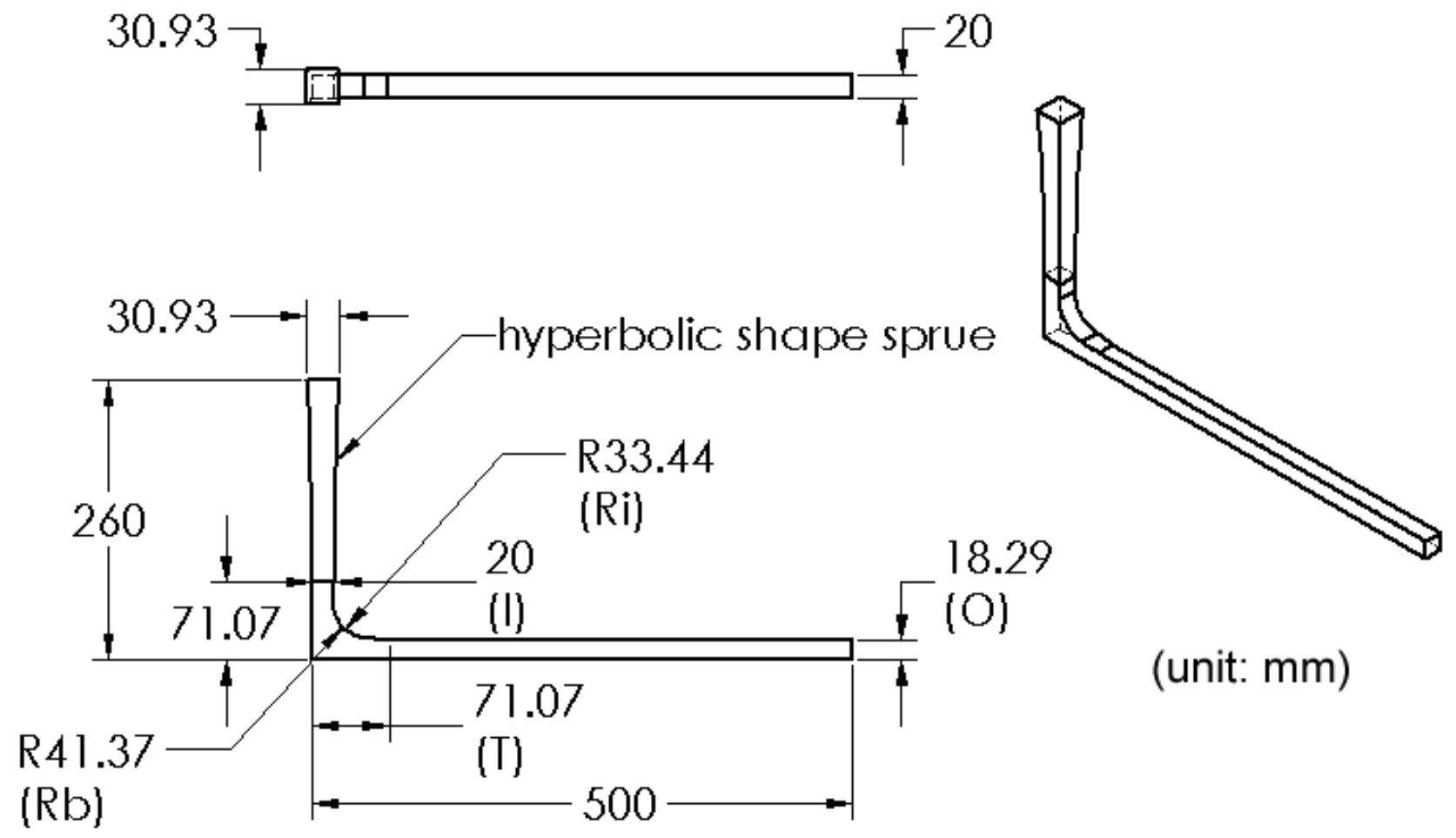

Figure 4 the simulation geometry for the 3-dimensional "L-shape" of the sprue-runner junction. 


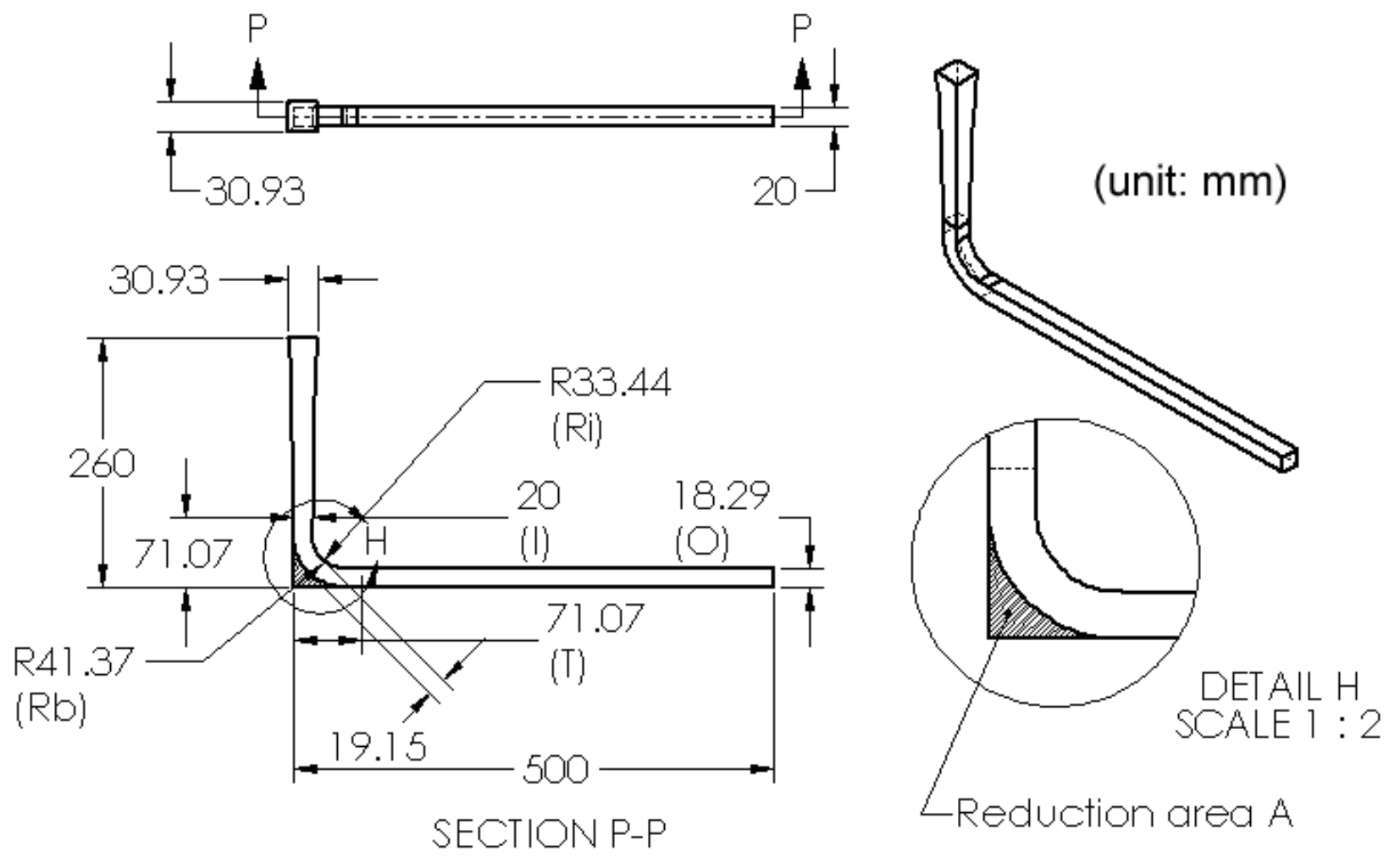

Figure 5 the simulation geometry for the 3-dimensional "Bend-shape" of the sprue-runner junction. 


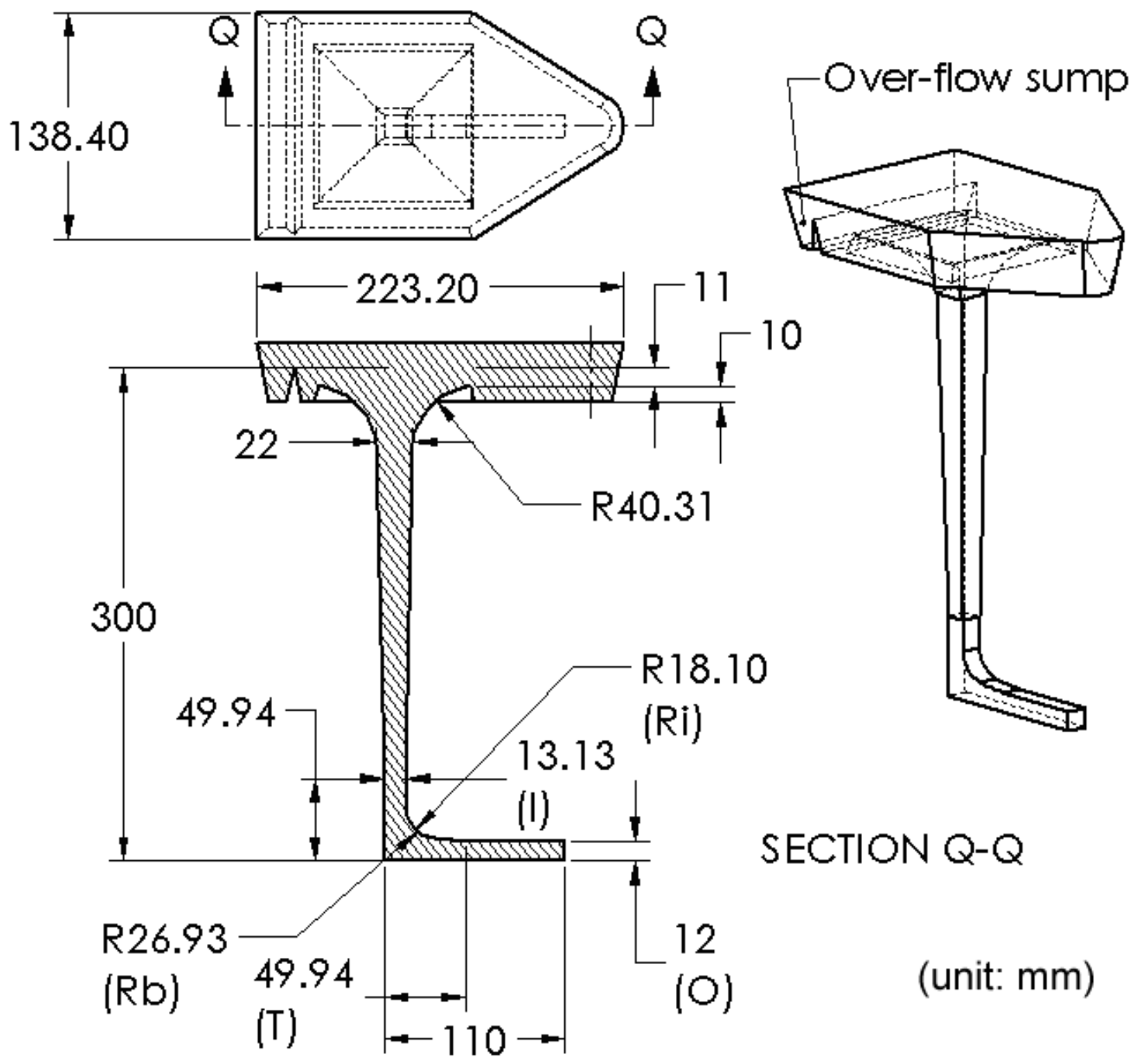

Figure 6 the dimensions of the casting experiment for the "sprue-runner junction". 

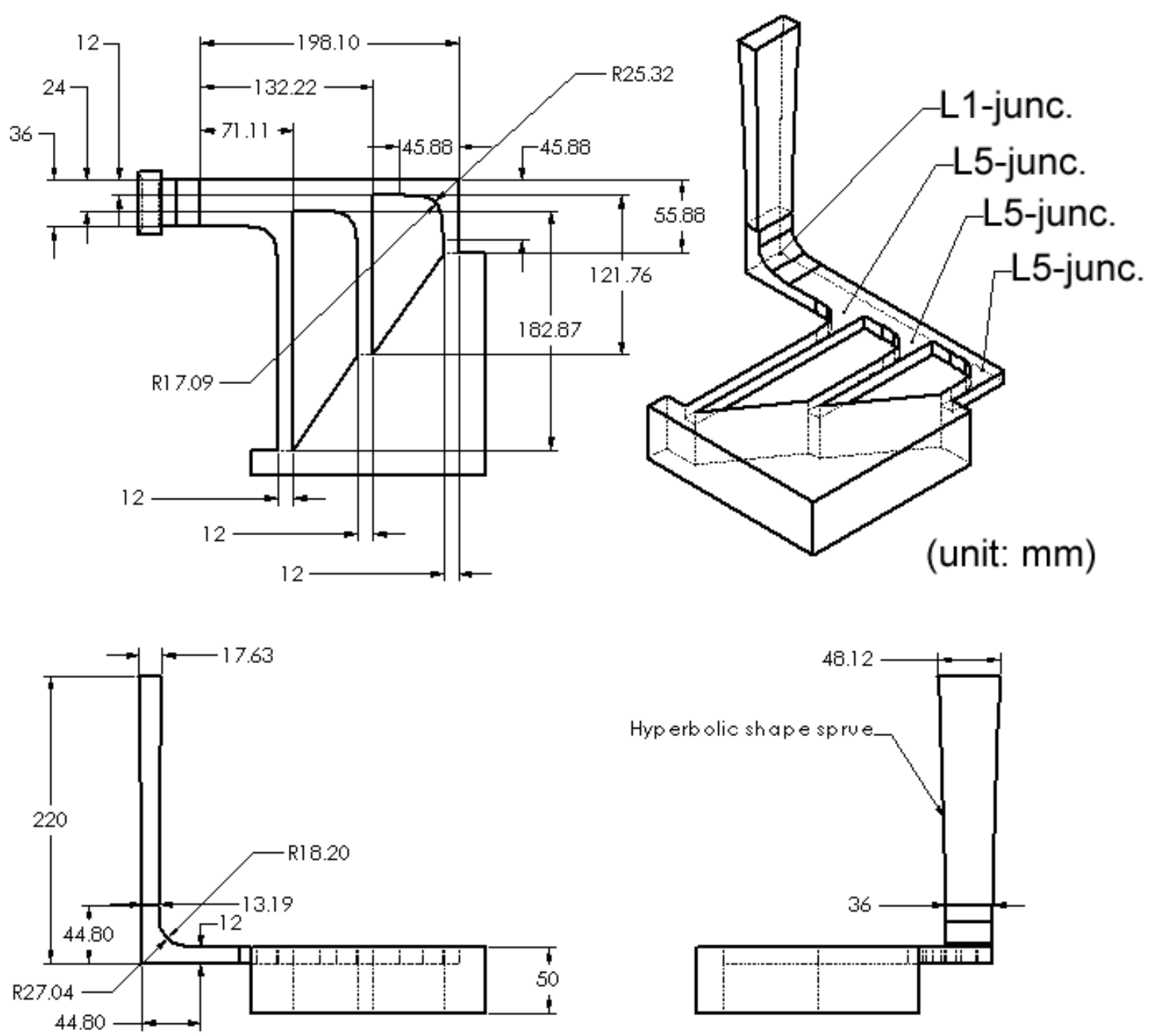

Figure 7 The dimensions for the simulation of the "Multiple-gates"; (the input velocity on top boundary of the domain is equvalent to a head hieght of $80 \mathrm{~mm}$, so that the total of height is therefore $300 \mathrm{~mm}$.) 


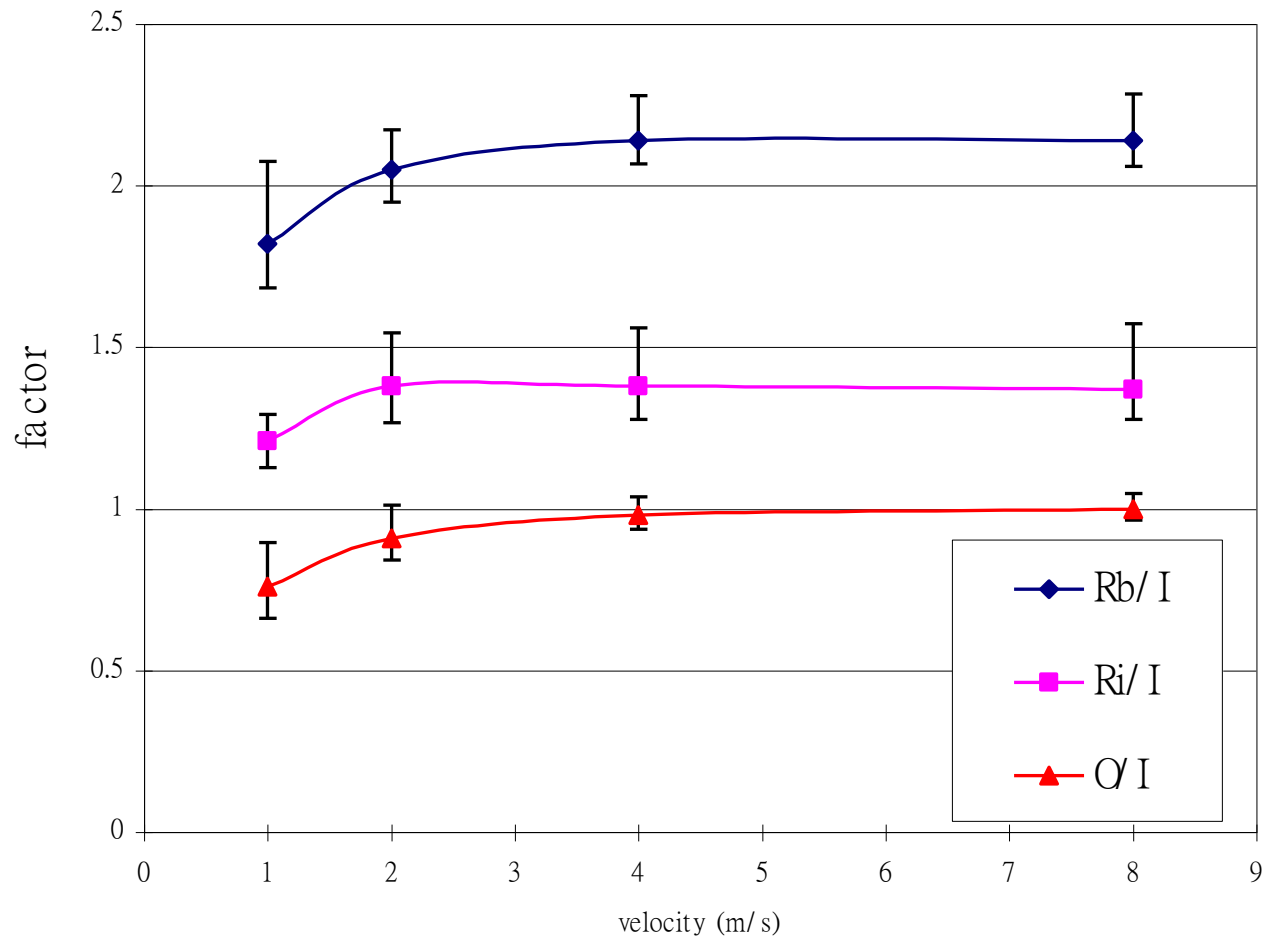

Figure 8 In the 2-D L1-junction, the dimensions; the base-radius Rb, the inner-radius Ri, outlet-dimension $\mathrm{O}$, normalised against the inlet-dimension I, as a function of inlet-velocity Vi. 
L1 - junction

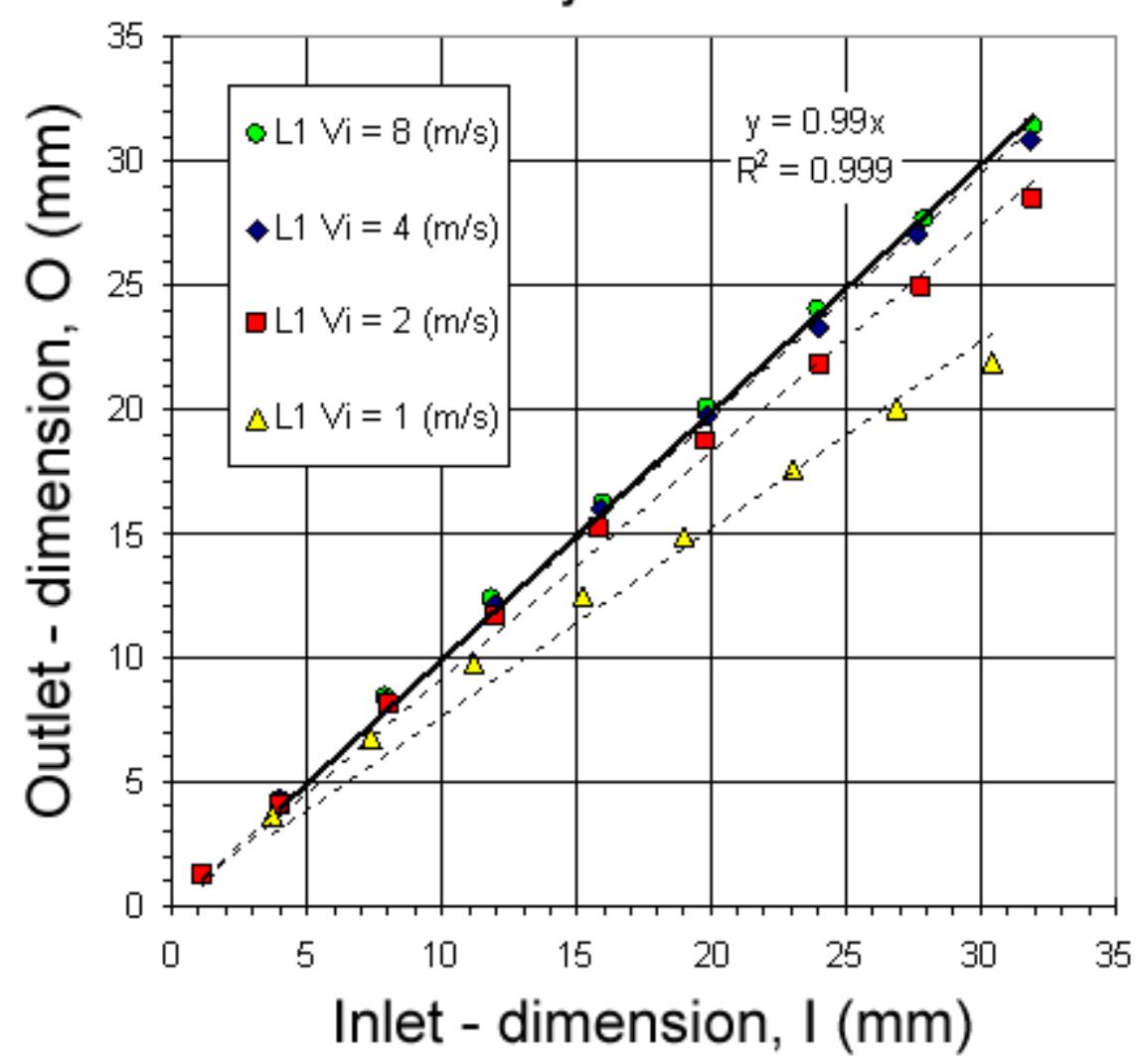

L5-junction

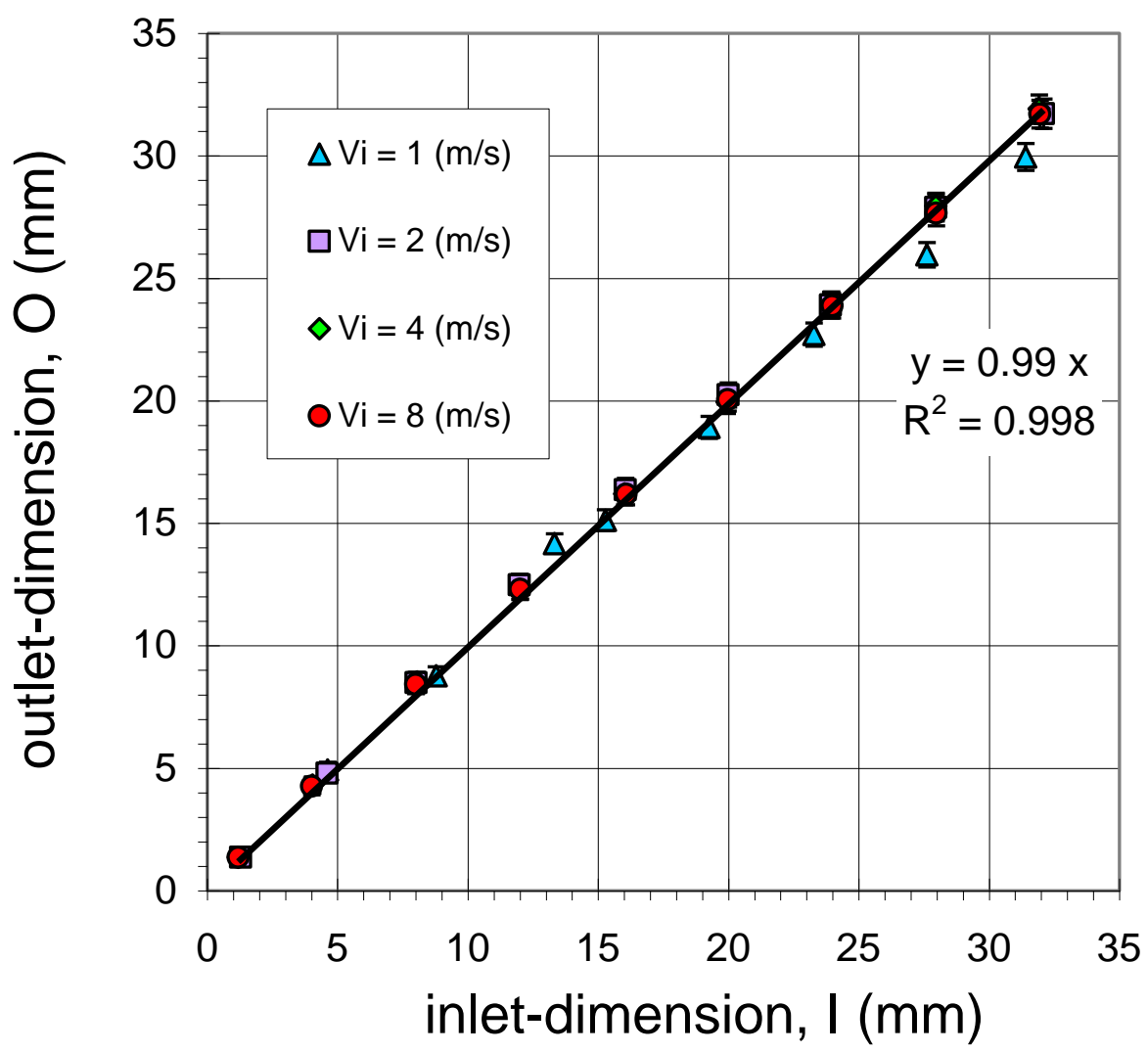

Figure 9 The outlet-dimension O versus inlet-dimension I for the L1 and L5 junctions with various inlet-velocity $\mathrm{V}_{\mathrm{i}}$ computed in 2D. 


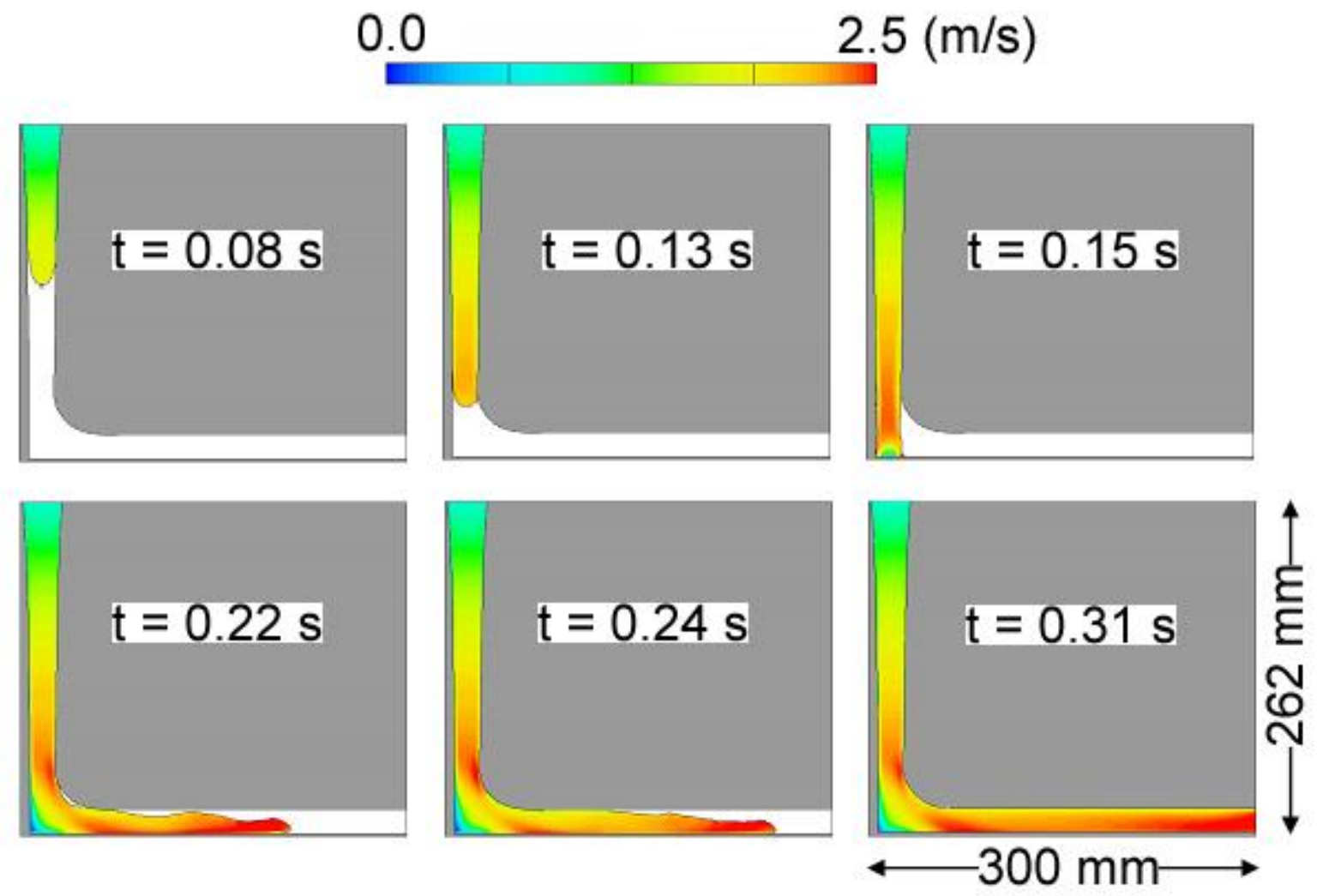

Figure 10 The modelling result of the 3D L-shape on the centre plane. The series of pictures of the "velocity magnitude contours" in the colour scale from $0.0 \mathrm{~m} \cdot \mathrm{s}^{-1}$ ( blue) to $2.5 \mathrm{~m} \cdot \mathrm{s}^{-1}$ (red). 


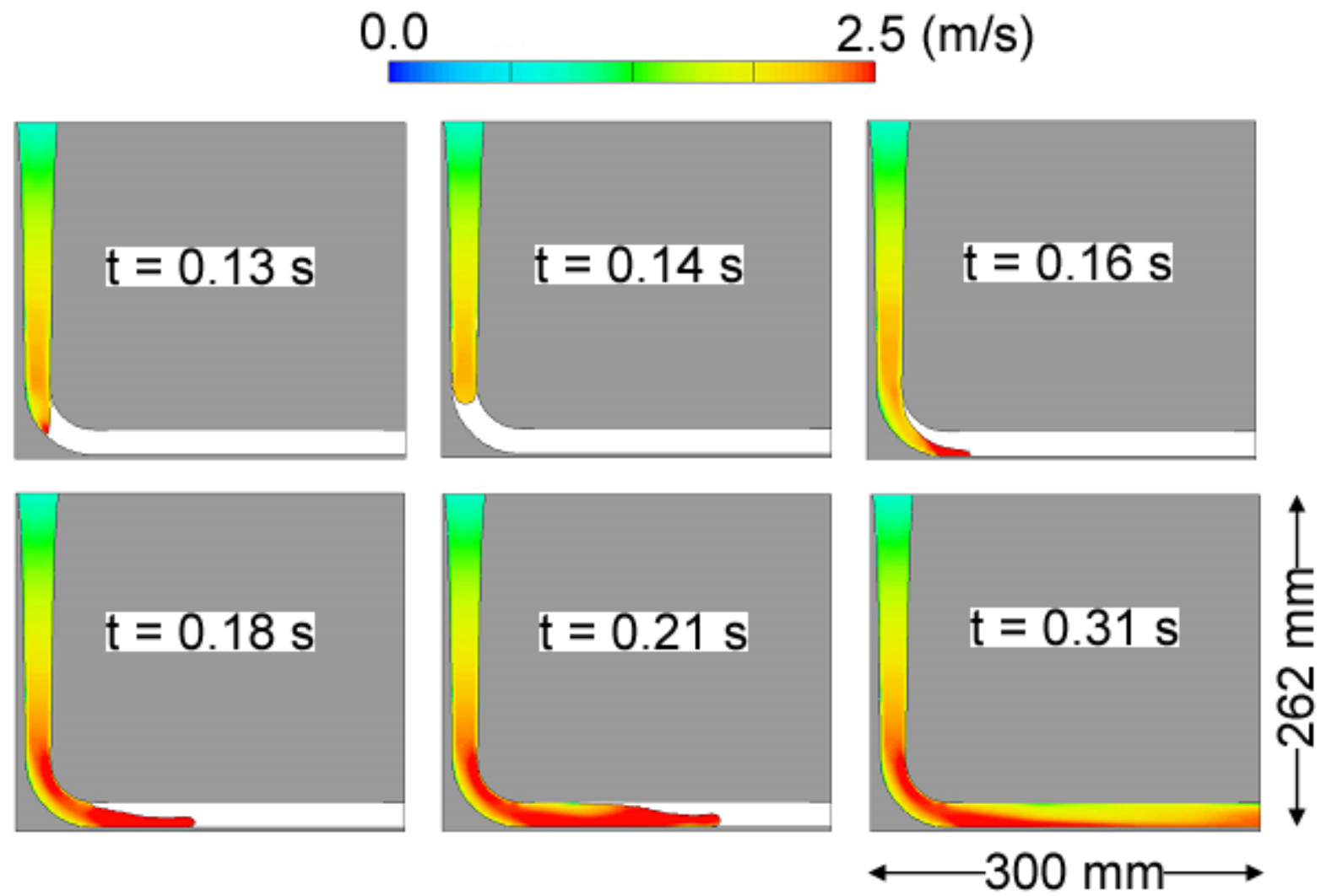

Figure 11 The modelling result of the 3D Bend-shape on the centre plane. The series of pictures of the "velocity magnitude contours" in the colour scale from $0.0 \mathrm{~m} \cdot \mathrm{s}^{-1}$ ( blue) to $2.5 \mathrm{~m} \cdot \mathrm{s}^{-1}$ (red). 


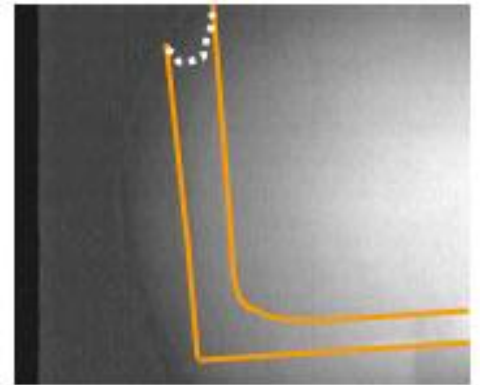

$\mathrm{t}=0.04 \mathrm{~s}$

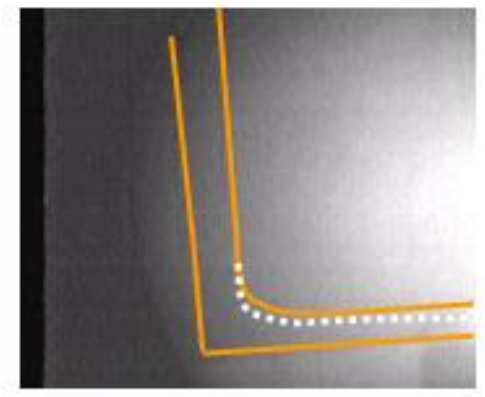

$t=0.24 \mathrm{~s}$

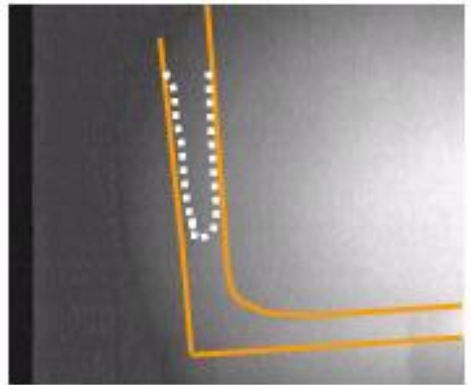

$$
\mathrm{t}=0.16 \mathrm{~s}
$$

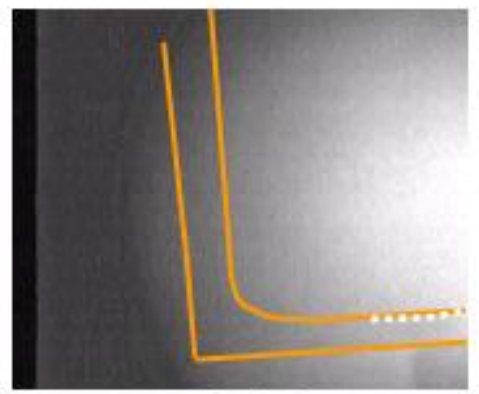

$t=0.28 \mathrm{~s}$

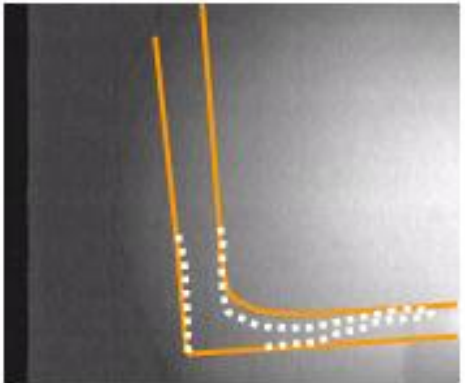

$\mathrm{t}=0.20 \mathrm{~s}$

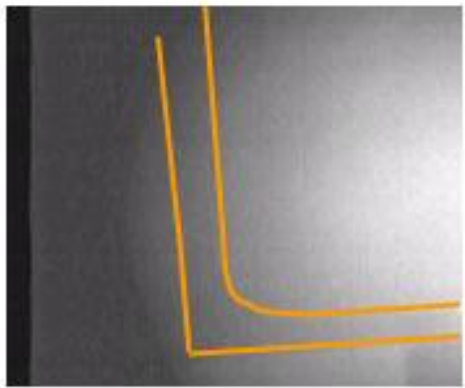

$t=0.32 s$

Figure 12 The experimental results of a series of real-time $\mathrm{X}$ - radiographies for the L-shape sprue-runner junction (single-gate system).
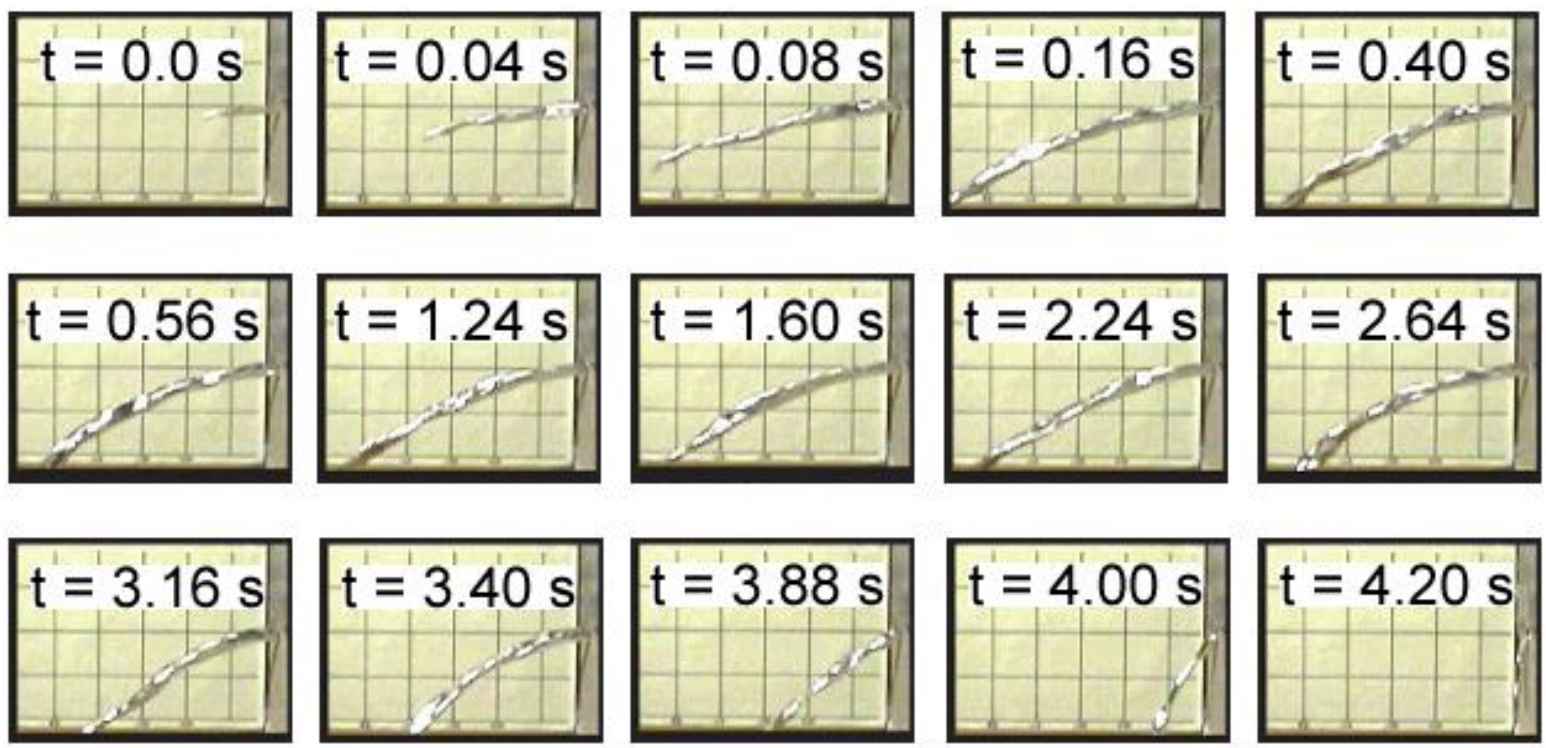

Figure 13 The trajectory method used for the estimation of the launch velocity $\mathrm{V}_{\mathrm{o}}$ of the stream issuing from the end of the L-shape sprue-runner design. 


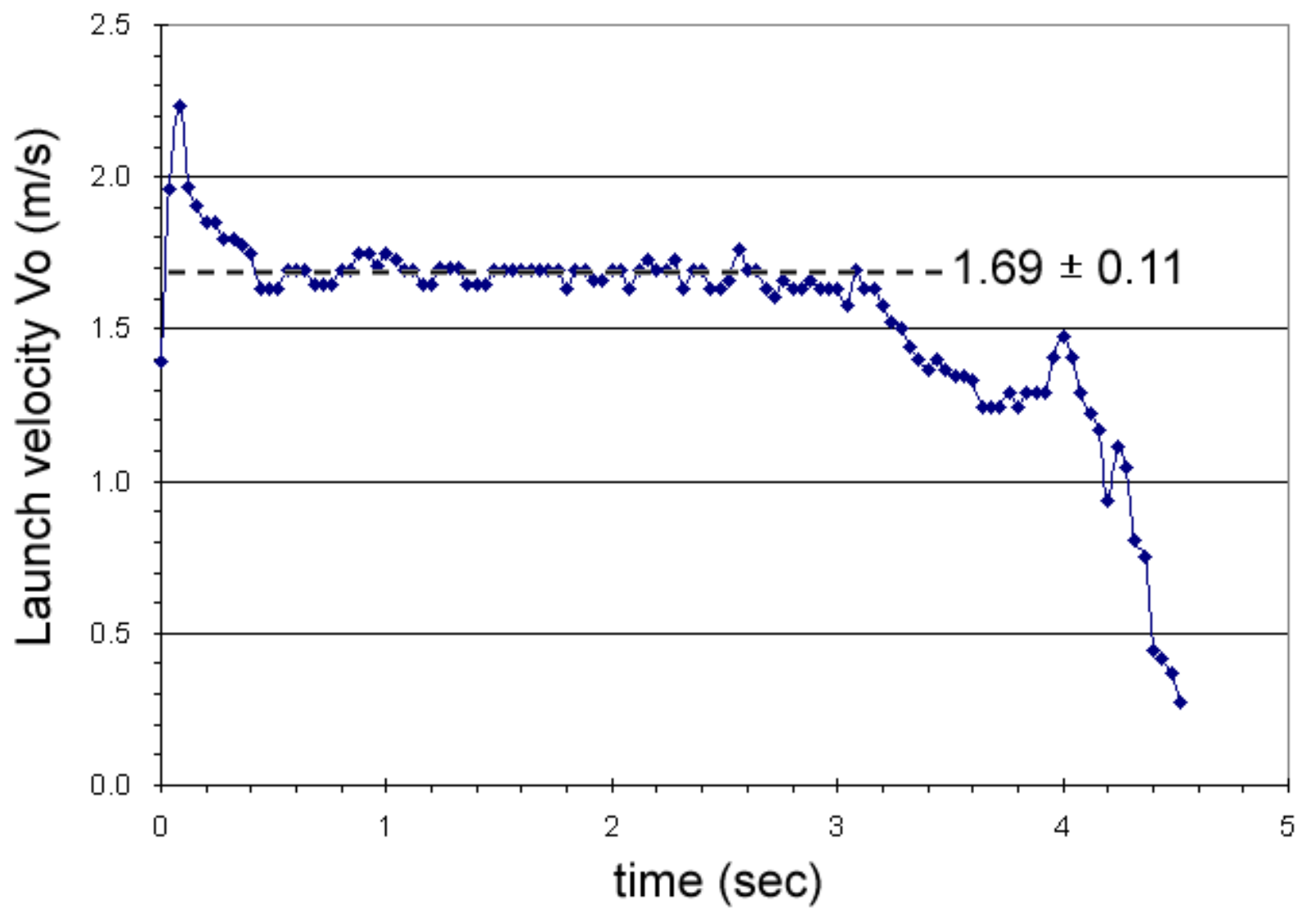

Figure 14 The estimation result of the launch velocity $\mathrm{V}_{\mathrm{o}}$ versus to time for the L-shape sprue-runner junction in real casting. 

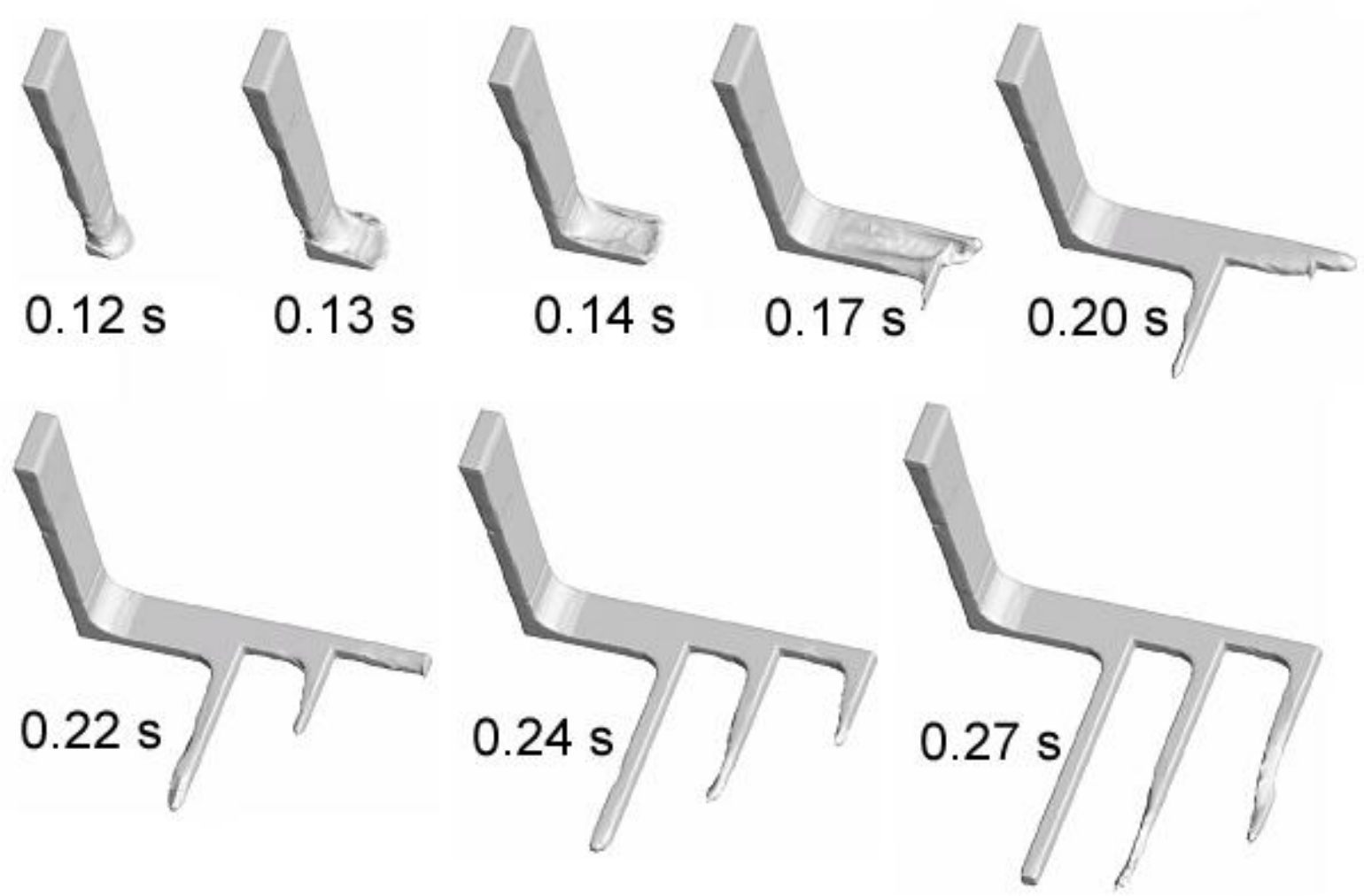

Figure 15 The modelling result of a series of pictures on the isotropic view of the multiple-gate design.

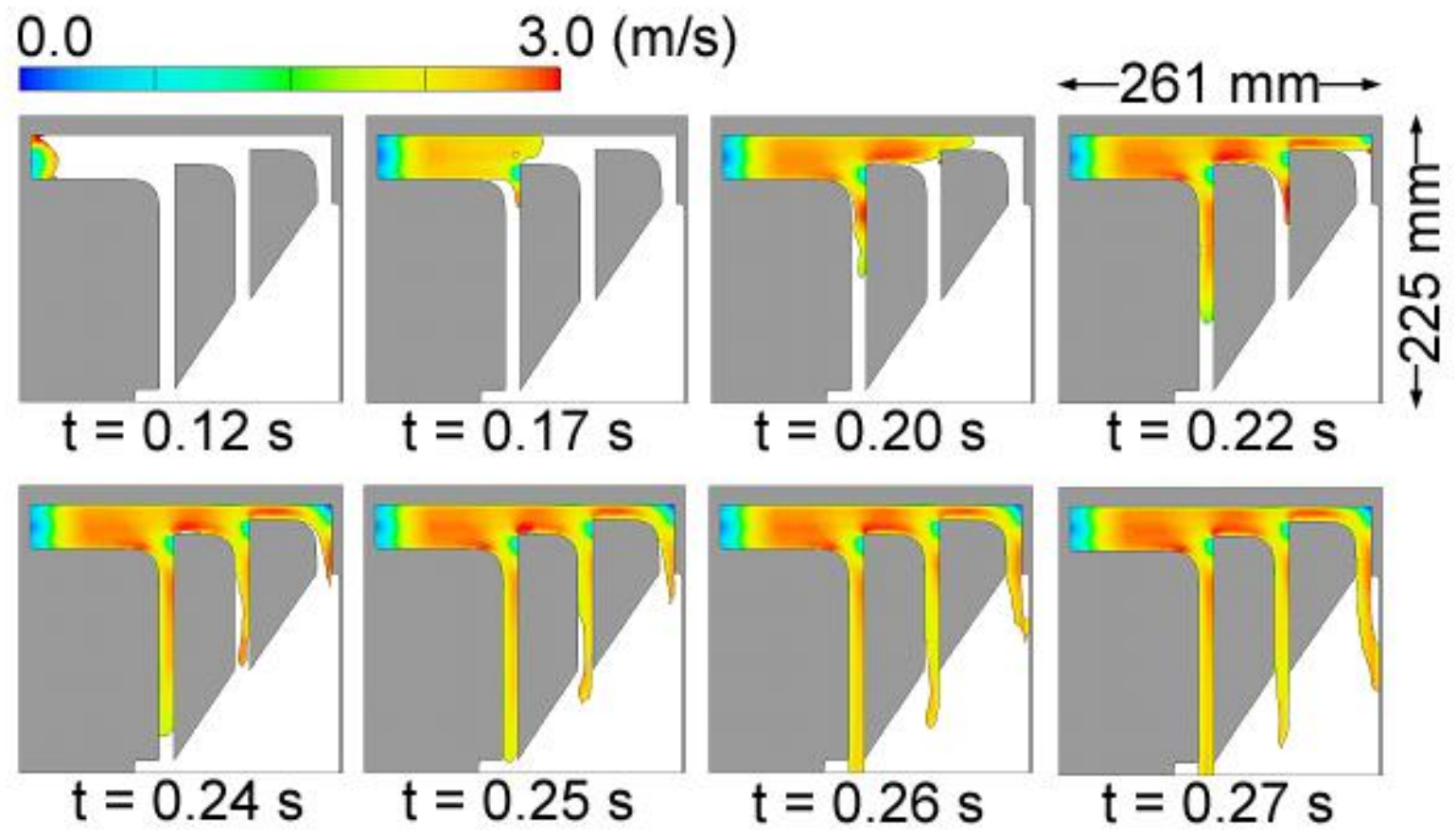

Figure 16 The modelling result of the multiple-gate design on the $x-y$ section in the plane $2 \mathrm{~mm}$ 
above the base of the sprue and the runner. The series of pictures of the "velocity magnitude contours" in the colour scale from $0.0 \mathrm{~m} \cdot \mathrm{s}^{-1}$ ( blue) to $3.0 \mathrm{~m} \cdot \mathrm{s}^{-1}$ (red).

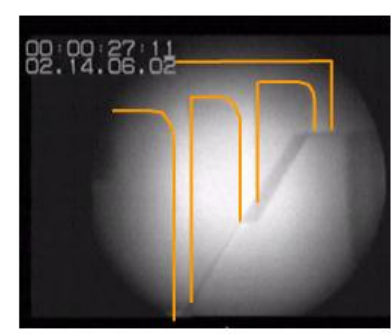

$t=0.0 \mathrm{~s}$

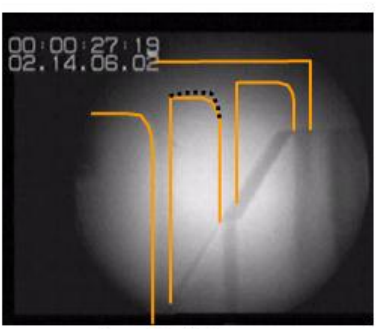

$t=0.32 \mathrm{~s}$

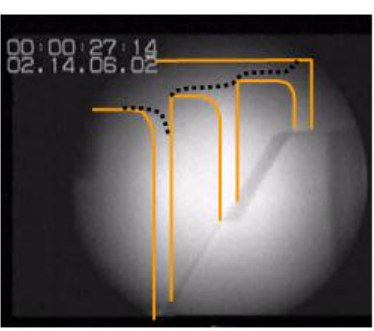

$t=0.12 \mathrm{~s}$

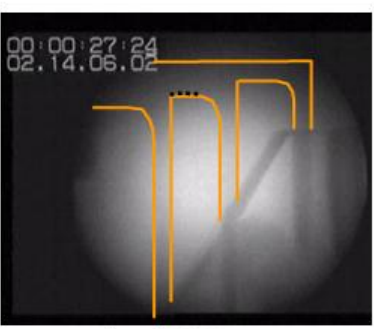

$t=0.52 \mathrm{~s}$

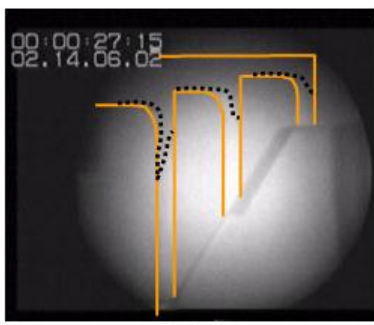

$t=0.16 \mathrm{~s}$

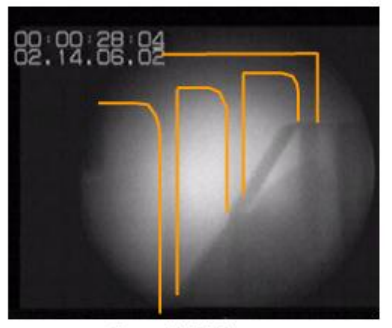

$t=0.72 \mathrm{~s}$

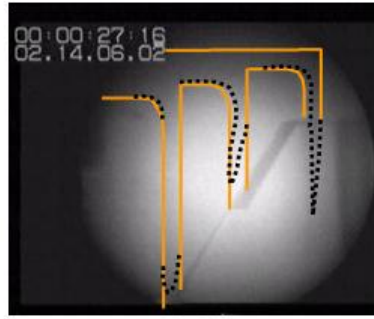

$t=0.20 s$

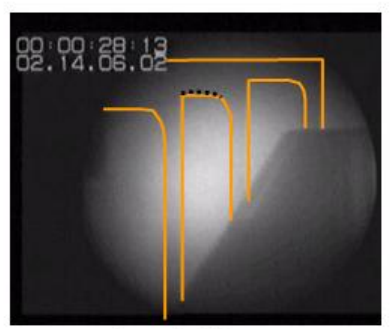

$t=1.08 \mathrm{~s}$

Figure 17 The experimental result of a series of real-time X-ray radiography images from the top view of the multiple-gate design. 

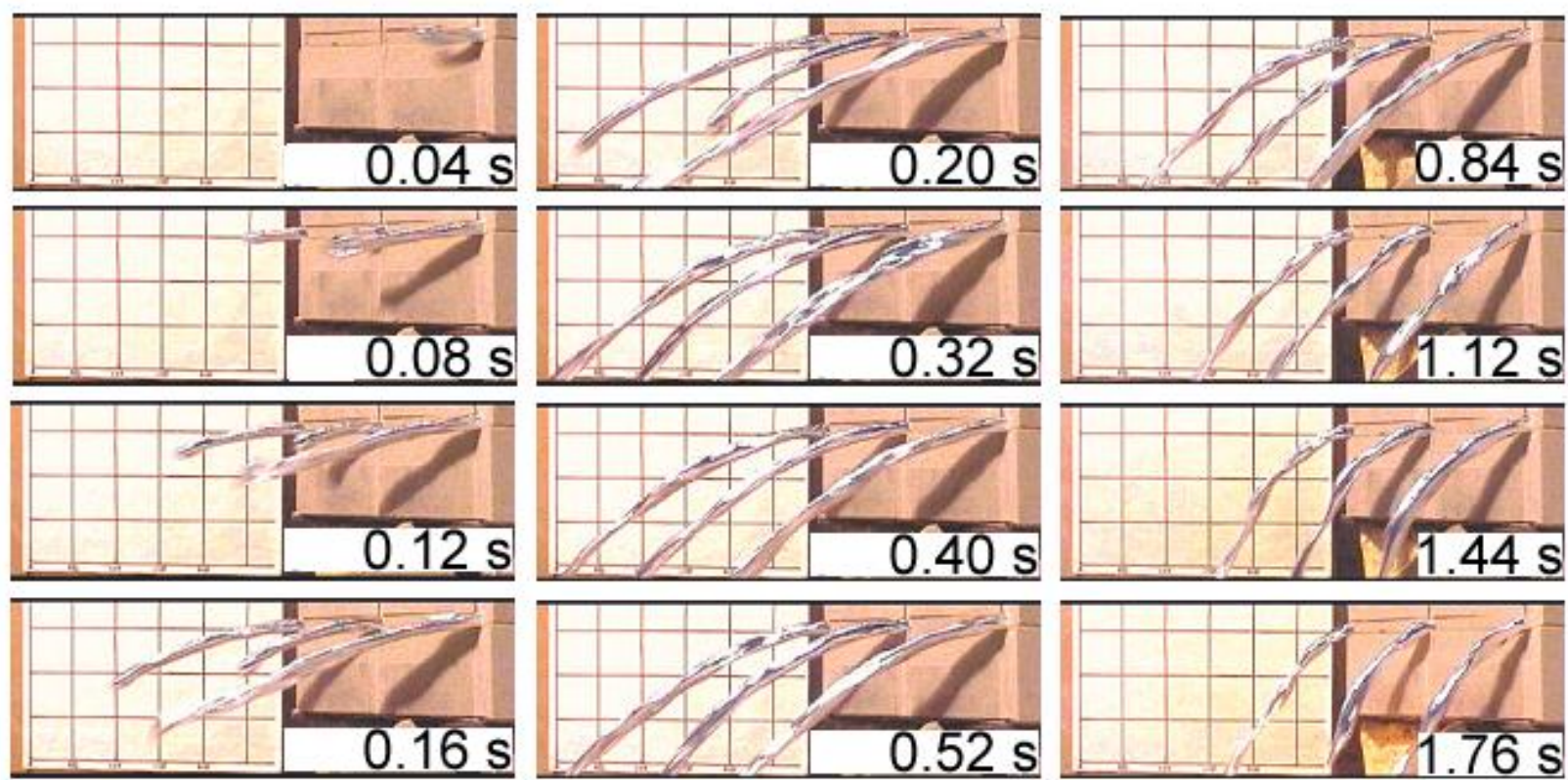

Figure 18 The trajectory method used for the estimation of the launch velocity $V_{o}$ of the three streams issuing from the end of the 3 gates of the multiple-gate design. 


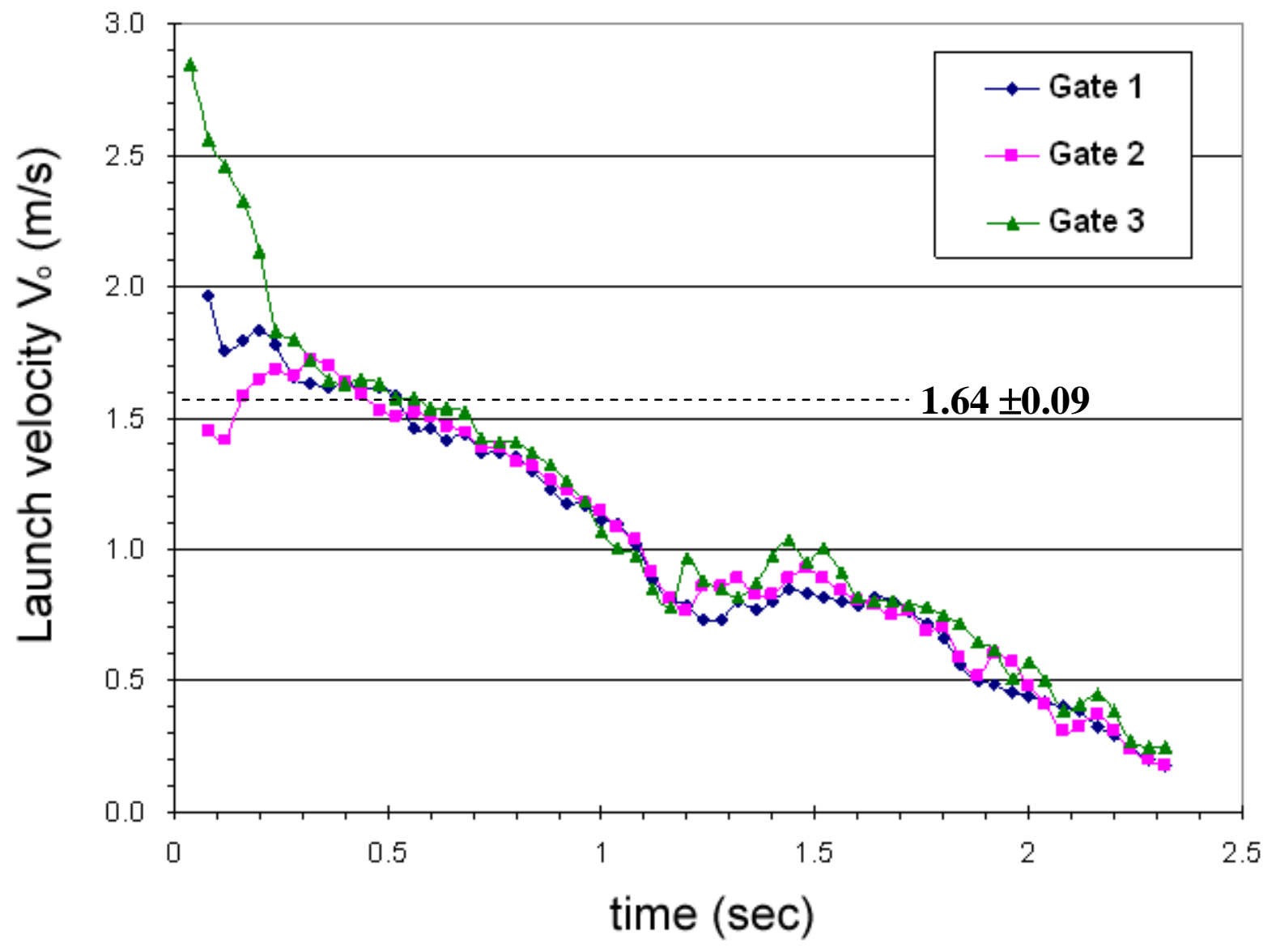

Figure 19 The estimation result of the launch velocity $\mathrm{V}_{\mathrm{o}}$ versus to time for the three streams issuing from the end of the 3 gates of the multiple-gate design. 
(a)

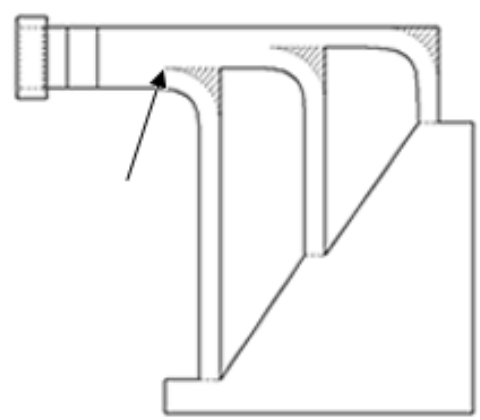

the tip of the bend (b)

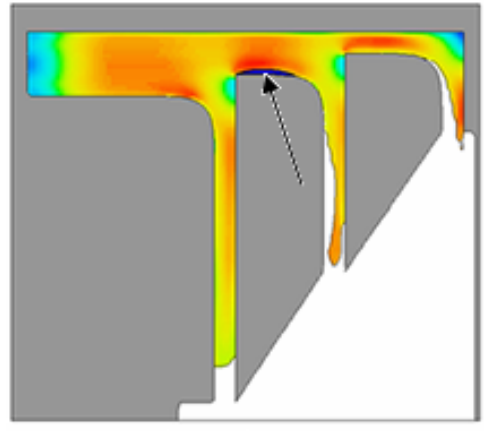

exact shape of wall (c)

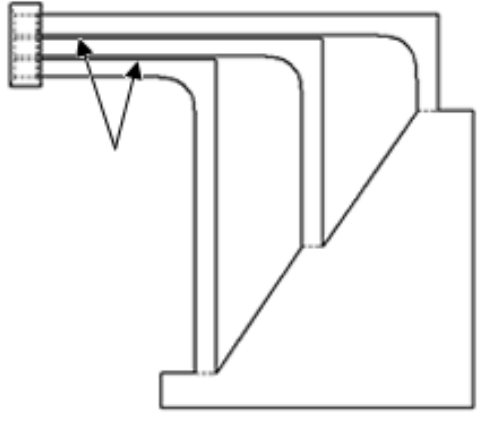

separated runners

Figure 20. Three ways for improvements of multiple gates runner reducing the influence of the dead zone region: (a) bend-shape in each L5- junction. (b) Exact shape of wall contacted with the main stream. (c) Separated runner.. 
Table 1 the dimensions of the $\mathrm{R}_{\mathrm{b}}, \mathrm{R}_{\mathrm{i}}$, and $\mathrm{O}$, normalised by I. (note: the values in parentheses are the R-squared values.)

\begin{tabular}{|c|c|c|c|}
\hline & $\mathrm{V}_{\mathrm{i}}\left(\mathrm{m} \cdot \mathrm{s}^{-1}\right)$ & L1-junction & L5-junction \\
\hline \multirow{4}{*}{$\mathrm{R}_{\mathrm{b}} / \mathrm{I}$} & 1 & $1.82(0.994)$ & \multirow{4}{*}{$\begin{array}{c}2.11 \\
(0.999)\end{array}$} \\
\hline & 2 & $2.05(0.998)$ & \\
\hline & 4 & $2.14(0.999)$ & \\
\hline & 8 & $2.14(0.998)$ & \\
\hline \multirow{4}{*}{$\mathrm{Ri} / \mathrm{I}$} & 1 & $1.21(0.996)$ & \multirow{4}{*}{$\begin{array}{c}1.42 \\
(0.993)\end{array}$} \\
\hline & 2 & $1.38(0.992)$ & \\
\hline & 4 & $1.38(0.993)$ & \\
\hline & 8 & $1.37(0.995)$ & \\
\hline \multirow{4}{*}{$\mathrm{O} / \mathrm{I}$} & 1 & $0.76(0.980)$ & \multirow{4}{*}{$\begin{array}{c}0.99 \\
(0.998)\end{array}$} \\
\hline & 2 & $0.91(0.996)$ & \\
\hline & 4 & $0.98(0.999)$ & \\
\hline & 8 & $1.00(0.999)$ & \\
\hline
\end{tabular}


Table 2 velocity head and head losses for each parts in the single-gate system of the L-shape jucntion.

\begin{tabular}{|c|c|c|c|c|c|}
\hline \multicolumn{2}{|c|}{ Parts } & $\begin{array}{c}\text { Head } \\
\text { height } \\
(\mathrm{m})\end{array}$ & $\begin{array}{c}\text { Loss coefficient, } \mathrm{K} \\
\text { or friction factor, } f\end{array}$ & Source of \\
coefficients & Others data for \\
calculations
\end{tabular}

